\title{
Experimental and molecular modelling study of the three-phase behaviour of (propane + carbon dioxide + water) at reservoir conditions
}

\author{
Esther Forte $^{\mathrm{a}}$, Amparo Galindo ${ }^{\mathrm{a}}$, J.P. Martin Trusler ${ }^{\mathrm{a}}$ \\ ${ }^{a}$ Department of Chemical Engineering, Imperial College London, London SW7 2AZ, UK.
}

\begin{abstract}
Acquiring a comprehensive understanding of the phase behaviour of mixtures of crude-oil with carbon dioxide and water is a key input for reservoir engineering in processes of enhanced oil recovery and geological storage of carbon dioxide. To gain an insight, given the very complex nature of crude-oil mixtures, the study of simpler systems is of interest. In this work the system (propane + carbon dioxide + water) has been chosen as a model (light oil fraction + carbon dioxide + water) mixture. Phase equilibrium measurements have been carried out using a quasi-static-analytical high-pressure apparatus that was validated on the system ( $n$-decane + carbon dioxide) in comparison with literature data, and used to study the system ( $n$-decane + carbon dioxide + water) [Forte, E.; Galindo, A.; Trusler, J. P. M.; J. Phys. Chem. B 115 (49)(2011) 14591-14609]. In the present work, new experimental data have been measured for the system (propane + carbon dioxide + water) under conditions of three-phase equilibria. Compositions of the three coexisting phases have been obtained along four isotherms at temperatures from (311 to 353) K and at pressures up to the upper critical end points where the propane-rich and the carbon dioxide-rich phases become critical. The experimental data obtained for the ternary mixture have been compared to the predictions obtained with the statistical associating fluid theory for potentials of variable range (SAFT-VR). The phase behaviour of each pair of binary subsystems has been calculated using this theory and, where applicable, a modification of the Hudson and McCoubrey combining rules has been used to treat the systems predictively. Furthermore, a detailed analysis of the phase behaviour of the ternary mixture has been carried out based on comparison with available data for the constituent binary subsystems, as well as with the previous findings for the ternary ( $n$-decane + carbon dioxide + water). Such comparison is useful to examine the effect that adding a third component has in the mutual solubility of each pair. Remarks relevant to reservoir processing are also highlighted.
\end{abstract}

Key words: Experimental data, Phase behaviour, SAFT-VR, Carbon dioxide, Water, Propane, Three-phase equilibria, Upper critical end point

\footnotetext{
* Corresponding author

Email address: m.trusler@imperial.ac.uk (J.P. Martin Trusler)

Preprint submitted to Journal of Supercritical Fluids
}

November 8, 2012 


\section{Introduction}

Knowledge of phase equilibria is crucial in the design and operation of chemical processes, including separation, purification and extraction. Operations such as distillation, gas absorption or supercritical extraction are a few examples in which details of such behaviour are necessary. In particular, $\mathrm{CO}_{2}$ plays an important role in supercritical fluid extraction [1]. Its excellent properties, such as non-toxicity, relatively low critical temperature and pressure, low cost and the possibility of being readily recovered and recycled, have made $\mathrm{CO}_{2}$ not only the most common solvent in supercritical extraction, but also a powerful alternative to harmful organic solvents. Among the most attractive applications of carbon dioxide is its use as an injection gas for enhanced oil recovery (EOR) purposes. $\mathrm{CO}_{2}$-EOR processes have been ongoing for around forty years $[2,3]$. Furthermore, when $\mathrm{CO}_{2}$ of anthropogenic origin is used in EOR, not only is oil recovery improved but also the $\mathrm{CO}_{2}$ may be sequestered in the reservoir.

The importance of understanding the miscibility and, in general the phase behaviour, of carbon dioxide with oil in the context of both $\mathrm{CO}_{2}$-EOR and $\mathrm{CO}_{2}$ storage processes was reviewed in our previous work [4]. In summary, the $\mathrm{CO}_{2}$ injected is likely to form two phases with the existing oil: a $\mathrm{CO}_{2}$-rich and an oil-rich phase. In addition water is a working-fluid that may have been previously injected as a displacement fluid or in alternating steps with the $\mathrm{CO}_{2}$ to improve the efficiency of the sweeping process. From a thermodynamic point of view the presence of water means that a third phase will typically coexist with the oil-rich and $\mathrm{CO}_{2}$ rich phases. It is generally understood that reservoir conditions mean high temperatures and high pressures (characteristic temperatures for diverse oil reservoirs may vary from $300 \mathrm{~K}$ to $410 \mathrm{~K}$ with initial conditions of pressure from $10 \mathrm{MPa}$ to $50 \mathrm{MPa}$ [5-9]), although such pressure conditions will obviously vary during the life of the reservoir. The essential input for $\mathrm{CO}_{2}$-EOR processes from phase equilibria measurements is however limited to pressures on the bubble-curve locus of hydrocarbons with $\mathrm{CO}_{2}$ in the presence of water. Regarding the sequestration of the $\mathrm{CO}_{2}$, although structural and capillary trapping are known to be the primary processes at play, dissolution of the $\mathrm{CO}_{2}$ is one of the long-term mechanisms for immobilizing $\mathrm{CO}_{2}$ in the reservoir. In numbers, solubility trapping prevails in a scale from ten to hundreds of years [10, chap.5] after injection.

Given the complexity of oil mixtures, a necessary step towards acquiring a comprehensive understanding of the behaviour of (oil + carbon dioxide + water) is the completion of a database comprising simpler hydrocarbon systems. In spite of the attention that binary combinations of alkanes, carbon dioxide and water have received, experimental data concerning ternary ( $n$-alkane + carbon dioxide + water)-type mixtures are sparse. The system ( $n$-hexadecane + carbon dioxide + water $)$ is the one with the heaviest hydrocarbon that has been studied [11]. In that study, mainly VLE was measured at temperatures between (473.15 and 573.15) $\mathrm{K}$ and pressures between (10 and 30) MPa, but also one experimental point was reported in the threephase equilibrium region at $473.15 \mathrm{~K}$ and $20 \mathrm{MPa}$ [11]. The system ( $n$-decane + carbon dioxide + water) 
was the focus of our earlier work [4], where three-phase vapour-liquid-liquid equilibrium (VLLE) data were measured at temperatures from (323 to 413) K and pressures from (1 to 18) MPa. The remaining studies found in the literature concern lighter alkanes. Among mixtures consisting of carbon dioxide with water and an alkane of low molecular weight, the system (methane + carbon dioxide + water) has been the most widely studied, not only regarding fluid-phase equilibria [12-15] but also fluid-hydrate equilibria [16-19]. Most of these fluid-phase equilibrium studies in ternary mixtures have focused on vapour-liquid equilibrium (VLE) and, with the exception of that of Qin et al. [12], only one phase composition was measured. In the study of Song and Kobayashi [15] measurements were made along the three-phase equilibrium locus, but only the $\mathrm{CO}_{2}$-rich phase was analyzed. Studies concerning ethane, propane or butane are fewer in number [13, 20]. The latter studies were focused on the determination of dew points of the mixtures at low temperature (below $289 \mathrm{~K}$ ) and pressure (up to $2.4 \mathrm{MPa}$ ) using a semi-flow apparatus. Regarding the system (propane + carbon dioxide + water) two experimental studies are reported in the literature, both focused on phase equilibrium with hydrates $[21,22]$ at temperatures up to $286 \mathrm{~K}[21,22]$. There appear to be no experimental data on vapour-liquid-liquid equilibrium (VLLE) for this system. Based on this study of the literature, we choose to study in this work (propane + carbon dioxide + water) as a model (light oil fraction + carbon dioxide + water) mixture with the objective of providing new VLLE measurements.

Aqueous systems of alkanes and/or $\mathrm{CO}_{2}$ present complex phase behaviour to be measured due to the low solubilities of these compounds in water for large temperature ranges below the critical temperature of water $(647 \mathrm{~K})$. The (propane + water) system exhibits type III phase behaviour in the classification of Scott and van Konynenburg [23, 24], typical of (alkane + water) mixtures as well as the system $\left(\mathrm{CO}_{2}+\right.$ water); type III phase behaviour is characteristic of very immiscible systems with a wide region of liquid-liquid equilibria that extends to high temperatures and pressures. For a comprehensive review on measurements of (carbon dioxide + water), the reader is referred to Refs. [25, 26]. Regarding systems consisting of various (hydrocarbons + water), it is worth highlighting the extensive work of Tsonopoulos et al. [27-31] as well as the IUPAC-NIST reviews [32-40], albeit both studies focused on heavier hydrocarbons than propane. For completeness, previous work on the (propane + water) mixture is here briefly reviewed. One of the earlier studies on the system (propane + water) is that of Poettman and Dean [41], who reported data on the water content of the vapour and the liquid alkane-rich phases of the system at conditions of three-phase coexistence. Data at VLLE conditions were later also obtained by Kobayashi and Katz [42] for the same system, including some VLE data at temperatures up to $420 \mathrm{~K}$ and $20 \mathrm{MPa}$. Sánchez and Coll [43] analysed the water-rich phase at conditions of two-phase equilibria involving high temperature, in the range from (530 to 660) K, and elevated pressure, from (20 to 330) MPa. Data for the propane-rich phase at VLE conditions were obtained by Blanco et al. [44] at low temperatures, from (250 to 280) K, and pressures <0.5 MPa, as well as by Song and Kobayashi [45] at similar conditions. More recently, data for the water-rich phase at VLE conditions has been obtained by Chapoy et al. [46] over a temperature range from (280 to 370$) \mathrm{K}$ and 
pressures $<4 \mathrm{MPa}$. Similarly, the water-rich phase has also been analysed by Mokraoui et al. [47] this time at VLLE conditions and at temperatures ranging from (300 to 340) $\mathrm{K}$ and pressures below $3 \mathrm{MPa}$. At low temperatures, the system also presents fluid-hydrate equilibria, which have been studied by a number of authors $[45,48,49]$. A further interesting feature typical of (alkane + water) systems is existence of gas-gas equilibria of the second type [50]; this was first identified in the (propane + water) system by de Loos et al. [51] at pressures up to $190 \mathrm{MPa}$. Measurements on the critical curve for this system were also carried by Brunner [50] at pressures up to $50 \mathrm{MPa}$ as part of an extensive study of the family of (alkane + water) mixtures.

In our previous manuscript [4], we discussed the necessity of having a reliable sampling technique to analyse aqueous mixtures of this type involving also components of different volatility. This was tackled with the design of an experimental apparatus with re-circulation, micro sampling and on-line chromatographic analysis. The same experimental equipment was used in the present work.

The interest in studying these aqueous mixtures is not restricted to their practical application and their experimental complexity, but reflects also the challenging nature of these systems from a modelling perspective. Associating theories such as the statistical associating fluid theory (SAFT) $[52,53]$ prove advantageous for modeling these highly non-ideal mixtures. Previous applications of associating theories to model (alkane + water) systems [54-65] and (carbon dioxide + water) [66-71] were reviewed in detail in our previous manuscript [4], to which the reader is referred for a complete analysis. Certain challenges were highlighted in these systems, such as the difficulty of modelling mutual solubilities of phases of very different nature, as represented by large variations between the dielectric constant of each phase and/or dipole moment of the molecules. Previous attempts to model the phase behaviour of ternary systems of the type of interest here are again limited, but the work of Míguez et al. [72] and Kontogeorgis et al. [73] on the system (methane + carbon dioxide + water) are of relevance. Two different models are used in these works. Míguez et al. [72] use the SAFT-VR equation of state with a limited adjustment of cross interaction parameters to have a global estimation of the phase diagram, while in [73] the cubic plus association (CPA) equation of state is chosen along with a different interpretation of the unlike interactions between $\mathrm{CO}_{2}$ and water, which are represented based on a cross-associating model.

In the remainder of this paper, the experimental procedure is described and new liquid-liquid equilibrium (LLE) and vapour-liquid-liquid equilibrium (VLLE) data for the system (propane + carbon dioxide + water) are presented. We compare our experimental findings with the predictions of SAFT-VR [74, 75]. We use this method as it has already been shown in a number of studies $[4,66,68,69,71,72,76-78]$ to provide an accurate description of the phase behaviour of mixtures consisting of alkanes, $\mathrm{CO}_{2}$ and water, for wide ranges of thermodynamic conditions. Finally, where possible, the agreement or deviations from published binary experimental data are further studied to analyse the effect of adding a third component and a third coexisting phase in the phase equilibria of the system. 


\section{Experimental}

In this work we use a high-pressure apparatus based on a quasi-static analytical technique [4]. The equipment relies on recirculation of two coexisting phases using a two-channel magnetically operated micro-pump, sampling and on-line chromatographic analysis. The main components, represented in Figure 1, are a highpressure view-cell, a magnetically coupled reciprocating pump (both fabricated in-house), electronicallyactuated sampling valves (Cheminert, model C2-2206EH3Y, and Valco, model DCI4UWT1Y, VICI AG International) and a gas chromatograph (Shimadzu, model GC-2014, Shimadzu Scientific Instruments, Inc.). A manual syringe pump (Sitec model 750.1100, SITEC-Sieber Engineering AG) was used for loading water; an automatic syringe pump (Teledyne Isco, model 100DM, Teledyne Technologies Inc.) was used for loading carbon dioxide. The remaining circuits shown in Figure 1 were used for purposes of venting, flushing and draining the system (valves V2 and V5). Loading of propane was done by means of an HPLC pump (Knauer Smartline Pump 1000, Wissenschaftliche Gerätebau Dr. Ing. Herbert Knauer GmbH) connected to V5 and refrigerated to a temperature of about $273 \mathrm{~K}$. The vessel, the reciprocating pump and the sampling valves were located inside a temperature-controlled oil bath.

\subsection{Materials}

The $\mathrm{CO}_{2}$ used in this work was $\mathrm{CP}$ grade supplied by BOC with a mole-fraction purity higher than 0.99995. The water was deionised to an electrical resistivity $>18 \mathrm{M} \Omega \cdot \mathrm{cm}$ at $T=298 \mathrm{~K}$ and was degassed immediately prior to use. The propane was supplied by CK Gas Products Ltd. with $>0.999$ purity. The carrier gas used for gas chromatography was CP-grade helium from BOC, with > 0.99999 purity.

\subsection{Experimental procedure}

The measurements were isothermal, with sequential analysis of each phase through composition measurements repeated a minimum of four times. The gas phase was sampled using the sampling valve GSV in Figure 1 and the liquid phases through the corresponding LSV together with a certain degree of tilt of the high-pressure cell to allow sampling of the middle phase [4]. A single column was sufficient to conduct the chromatographic analysis of the (propane $+\mathrm{CO}_{2}+$ water) mixture. The column used was a HayeSep Q with $80 / 100$ mesh $(2 \mathrm{~m} \times 3.2 \mathrm{~mm}$ o.d. $\times 2 \mathrm{~mm}$ i.d., silcosteel lined to reduce adsorption $)$. The operating conditions of the GC are summarised in Table 1.

\subsection{Experimental results for (propane + carbon dioxide + water $)$}

The majority of the experimental data gathered in this work correspond to three-phase VLLE composition values. Data for four isotherms at $T=(311,323,338$ and 353$) \mathrm{K}$ and pressures from the vapour pressure of propane to the critical pressure between the propane-rich and $\mathrm{CO}_{2}$-rich phases have been obtained. The VLLE data are reported in Table 2. Additionally, in Table 3 the LLE data obtained at the critical 
pressure between the propane-rich and the carbon dioxide-rich phases in coexistence with the water phase are presented.

The combined standard uncertainty in the composition measurements $u_{c}\left(x_{i}\right)$ was calculated based on estimations of the contributions arising from the calibration of the chromatograph, and from uncertainties in pressure and temperature measurements as follows [79]

$$
u_{c}^{2}\left(x_{i}\right)=\left(\frac{\partial x_{i}}{\partial p}\right)^{2} u^{2}(p)+\left(\frac{\partial x_{i}}{\partial T}\right)^{2} u^{2}(T)+\sum_{j=1}^{3}\left(\frac{\partial x_{i}}{\partial n_{j}} \frac{\partial n_{j}}{\partial A_{j}}\right)^{2} u^{2}\left(A_{j}\right)
$$

where $u(p), u(T)$ and $u\left(A_{j}\right)$ are the standard uncertainties related to the pressure, temperature and calibration of the chromatograph for component $j$, respectively. The estimated uncertainties are $u(p)=10 \mathrm{kPa}$, $u(T)=0.05 \mathrm{~K}$ and $u\left(A_{j}\right) / A_{j}=0.02$, the latter referred to the given chromatographic area. The combined standard uncertainty in the composition measurements is summarised in Table 4. Standard deviations were used to account for a second class of uncertainty, based on the repeatability of the measurements as a result of random sources of error. Both types of uncertainty were combined to obtain the overall uncertainties presented also in Table 4.

\section{Models, theory and calculations}

In the case of mixtures where only limited experimental data are available at the outset, such as this one, a sophisticated equation of state is an essential tool to guide experiments and choose state points to be measured. In this work we rely on the SAFT-VR approach for this purpose. Within the SAFT-VR formalism $[74,75]$, molecules are modelled as associating chains of tangentially bonded spherical segments interacting through attractive potentials of variable range. Chains of $m$ tangent spheres of diameter $\sigma_{i i}$ that interact through square-well potentials of well-depth $\varepsilon_{i i}$ and range $\lambda_{i i}$ are considered. Hydrogen bonding interactions are mediated by adding short-range off-center associating sites to the molecules. These interact through attractive square-well potentials of energy $\varepsilon_{i i}^{\mathrm{HB}}$ and cut-off range $r_{c}{ }_{i i}^{\mathrm{HB}}$; each of these sites is placed at a distance $r_{d} / \sigma=0.25$ from the centre of the segment.

\subsection{Pure components}

The models used here for the pure components are based on previous works. Propane is modelled as a homonuclear chain comprising a number of segments based on a previous parametrization for the alkane family [80-82], $\mathrm{CO}_{2}$ is modelled as a non-associating molecule comprising two identical spherical segments [76, 77] and water is modelled as a single sphere with four off-centre square-well association sites, as this was found to be the most appropriate model to describe the hydrogen bonding interaction based on thermodynamic and spectroscopic data [83]. The intermolecular model parameters used here were obtained in earlier works by comparison with experimental vapour pressure and liquid density data for each component in a range from the triple point to $90 \%$ of the critical temperature. 
It should be noted at this point that SAFT-VR, like any other classical equation of state, is a mean-field theory and therefore does not account for density fluctuations. Such a mean-field description is known to fail in the proximity of critical points, where long-range density fluctuations characterise the behaviour. Appropriate treatments to incorporate a description of critical fluctuations have been presented for the SAFT-VR equation [84-89], but these are not considered in this work. In practice, the mean-field description typically leads to an over-prediction of temperature and pressure in the critical region. In this work, it was considered useful to use molecular parameters re-scaled to the experimental critical point of carbon dioxide and propane. These re-scaled models for propane and carbon dioxide were obtained [76, 77] by adjusting the conformal parameters $\left(\sigma_{i i}\right.$ and $\left.\varepsilon_{i i}\right)$ to match the experimental critical temperature and pressure. It is worth mentioning here that in practice this re-scaling to the critical point is done at the expense of a loss in the accuracy of the calculations in the low temperature and high-density region. Because the conditions of interest are far from the critical point of water, the intermolecular parameters of this component were not re-scaled, so that a major loss of accuracy in the region of interest was avoided. The SAFT-VR parameters for the three pure components are collected in Table 5.

\subsection{Mixtures}

The application of SAFT-VR to mixtures requires, as any other equation of state, the determination of a number of unlike interactions [75, 90]. These are typically expressed based on simple arithmetic or geometric-mean rules. However, for an accurate representation of complex mixture phase behaviour, often two adjustable parameters need to be included. These two parameters, $k_{i j}$ and $\gamma_{i j}$, related to the unlike depth and range of the square-well potential, respectively, are typically determined by comparison with experimental data. State independent parameters are considered throughout this work.

\subsection{1. (Propane + carbon dioxide)}

The system (propane + carbon dioxide) is modelled using an arithmetic-mean rule for the unlike range of the potential [75], and so the corresponding adjustable parameter is set to zero $\left(\gamma_{i j}=0\right)$. The $k_{i j}$ parameter is not adjusted, but an appropriate value is calculated using an extended version of the Hudson and McCoubrey combining rules [90]. These are based on a generalisation of those of Hudson and McCoubrey for application to square-well potentials and incorporating a further treatment of polar interactions (e.g., the effect of dipolar, quadrupolar and association interactions are accounted for in addition to the usual London-dispersion attraction) [90]. In the calculation of the $k_{i j}$ parameter using these combining rules, we account for the quadrupole moment of the $\mathrm{CO}_{2}$ molecule, taken as [91] $Q=-1.4 \times 10^{-39} \mathrm{C} \cdot \mathrm{m}^{2}$, whereas the dielectric constant of the media is assumed to be constant and equal to unity, based on actual values at the temperatures of study [92]. The ionization potentials of propane and $\mathrm{CO}_{2}$ are taken to be [92] $I_{1}=$ $1.8 \times 10^{-18} \mathrm{~J}$ and $I_{2}=2.2 \times 10^{-18} \mathrm{~J}$. The final value determined by the generalised Hudson and McCoubrey 
combining rules for the binary interaction parameter is $k_{i j}=0.082$. Use of this value allows for a successful prediction of the phase diagram of the system, as seen in Figure 2. The global phase behaviour that is predicted is also shown in Figure 2(b), as the critical curve for this system appears within the range of conditions of interest to this work.

\subsubsection{Aqueous systems: (propane + water) and (carbon dioxide + water)}

The application of the extended Hudson and McCoubrey combining rules to aqueous systems leads to a strong state-dependency of the $k_{i j}$ parameter [90]. This is due to the variations of the dielectric constant in each phase and of the permanent dipole moment of water with temperature and density, as well as the temperature dependency of the Keesom term describing the permanent dipole-dipole interactions between water molecules. In this work, the unlike interaction parameters were instead adjusted by comparison with experimental data in the region of interest so as to have temperature- and phase-independent values. In the optimisation, experimental data [42] for both the aqueous and the propane-rich phase in a range of temperatures from (310 to 360) $\mathrm{K}$ and pressures from (0.5 to 20) MPa were used. However, as predicted by the extended Hudson and McCoubrey combining rules [90], an accurate prediction of both the aqueous and the alkane-rich phases with a single interaction parameter is not easily achieved. If only the common binary interaction parameter $k_{i j}$ is used for (propane + water), the best agreement with experiment, obtained with $k_{i j}=0.3006$ and shown in Figure 3, leads to a considerable underestimation of the solubility of propane in the aqueous phase (predicted in the order of $x_{1} \sim 10^{-11}$ ). If the second interaction parameter $\left(\gamma_{i j}\right)$ is adjusted, a good compromise for both phases can be obtained, albeit at the expense of some loss in the accuracy of the alkane-rich phase (see Figure 3 for the case with parameters $k_{i j}=-0.99$ and $\gamma_{i j}=0.2225$ ). Although the value for the cross dispersion parameter $\left(k_{i j}\right)$ seems excessive, we have confirmed that these values of cross interaction parameters lead to the type III phase behaviour that is expected [50, 51]. For a fairer comparison of the combined correction of both parameters, we can calculate the attractive van der Waals constant. This parameter values presented correspond to a correction for the attractive van der Waals constant (calculated with Lorentz-Berthelot combining rules) equal to 0.37. A comparable correction of 0.4 would correspond if the initial parameter set $\left(k_{i j}=0.3006\right.$ and $\left.\gamma_{i j}=0\right)$ were used. Additionally, a check with the Hudson and McCoubrey combining rules suggests that large negative values (close to $k_{i j}=-0.7$ ) are necessary to model the water-rich phase at the temperatures of study; similar values have also been suggested for the (methane + water) system [90].

For the system (carbon dioxide + water) the second interaction parameter $\gamma_{i j}$ is also used. The parameters ( $k_{i j}=-0.6228$ and $\left.\gamma_{i j}=0.1358\right)$ were obtained by fitting to experimental data [93-95] for the aqueous and the carbon dioxide-rich phases of the mixture at $T=323.15 \mathrm{~K}$ in a range of pressures from (0.1 to 18) MPa. As before, although these correcting factors seen rather large we have confirmed that they lead to type III phase behaviour and that they would correspond to a correction of 0.12 in van der Waals-Lorentz-Berthelot 
terms. The predicted phase behaviour at $T=308.15 \mathrm{~K}$ is shown in Figure 4. Comparison with a previous set of parameters where the $\gamma_{i j}$ interaction parameter is set to zero is also shown for completeness.

\section{Discussion}

The binary subsystems (propane + carbon dioxide), (propane + water) and (carbon dioxide + water) are known to be of type I, III and III, respectively, in the classification of Scott and van Konynenburg [23, 24]. The result of such a combination leads to a ternary system (propane + carbon dioxide + water) that may be considered of type VI in the classification of ternaries suggested by Bluma and Deiters [96]. This type of phase behaviour is characterised by a surface of liquid-liquid critical points that spans from the critical point of the less volatile component (water) and increases with pressure. At lower pressures and temperatures, a second critical surface can be found that connects the critical points of propane and carbon dioxide and ends at an upper critical end line. Regions of vapour-liquid-liquid three phase coexistence can thus be found at conditions below the upper critical end line. In Figure 5 an isotherm is plotted. For a given temperature, the VLLE region starts at the vapour pressure of propane and ends up at the upper critical end point that corresponds at that temperature. It can also be seen in the figure that regions of three phase equilibria represent only a small percentage of the diagram, which is mostly characterised by two-phase coexistence regions of vapour-liquid (i.e., in the carbon dioxide-rich side and below the upper critical end point conditions) or liquid-liquid. These VLLE regions are further presented in Figure 6 for the four isotherms measured, where both the experimental data and the corresponding SAFT-VR calculations are shown. In general, similarities in volatility and size between the molecules of propane and carbon dioxide may result in a relatively broad miscible range; this is reflected in the diagrams by a relatively narrow VLLE region. This is more obvious if the general appearance of the diagram for the (propane + carbon dioxide) system is compared with that for ( $n$-decane + carbon dioxide + water) [4]; in the second case the VLLE region is markedly wider and spans to higher pressures.

Points along the upper critical end line, where the propane-rich and the carbon dioxide-rich phases become critical in presence of the water-rich phase, have also been measured for this system (cf. Table 3). The experimental upper critical end point at each temperature was observed to be associated with a colorful opalescence. The critical pressure was obtained visually, and the composition measurement of the coexisting phases was carried out at slightly higher pressure, following the procedure previously discussed [4]. To complete the analysis of the ternary mixture, the effect of adding a third component in each binary subsystem is studied in the discussion that follows, through comparison of the data measured for the ternary system with published data for each binary. 


\subsection{Influence of water on the phase behaviour of (propane + carbon dioxide)}

In general the presence of a third aqueous phase and the dissolution of part of the water in the propane-rich and carbon dioxide-rich phases does not result in any large effect on the equilibrium between propane and carbon dioxide. This is shown in Figure 7 for two isotherms $(T=311.10 \mathrm{~K}$ and $T=323.01 \mathrm{~K})$ based on the available binary data at the temperatures of study.

The locus of the upper critical end points is depicted in Figure 8. A general agreement between our experimental data, which correspond to upper critical end points between the carbon dioxide-rich and propane-rich phases, and published critical points for the binary (propane + carbon dioxide) is observed. The theory predicts a gentle trend towards a higher critical pressure, if the calculations for the ternary and the binary are compared (see Figure 8), but this mild discrepancy seen with the theory seems to keep within experimental uncertainty. It can be concluded that the effect of water on the mutual solubilities of (propane + carbon dioxide) is very small under the conditions investigated.

\subsection{Influence of carbon dioxide on the phase behaviour of (propane + water)}

The effect of adding carbon dioxide to the water-rich phase of the (propane + water) system is first analysed. In Figure 9 the solubility of propane in the water phase of the ternary system is compared to that in the binary system. In spite of the scatter of the data, it can be concluded that the solubility of propane in water increases when carbon dioxide is also present. This observation is consistent with the effect seen in the corresponding phase of the (decane + carbon dioxide + water) system [4]. Interestingly, the theory predicts lower solubilities than for the corresponding binary. At a given temperature, the trend of experiments and theory shows some consistency as the pressure increases. This is especially obvious at the lowest temperature, where it is clear that the higher the pressure the lower the solubility for both experiments and theory for the ternary. Comparing now isotherms, there is also a general trend towards an increase in solubility as the temperature raises, an observation that is again consistent with the theory for the ternary and with the behaviour shown by the published binary data in the LLE region. Focusing now only on the solubilities of propane in the binary system, there is again a trend that is not predicted by the theory in comparison to the published experimental data. We are referring to the crossover that is experimentally seen if isotherms in the VLE region are compared with those in the LLE region. In the LLE region, the measured solubility increases with temperature, whereas in the VLE region it decreases. The theoretical calculations for the binary predict a decrease of solubility with temperature in both regions.

Regarding the effect of carbon dioxide on the solubility of water in the alkane-rich phase, the experimental results for the ternary seen in Figure 10 show a trend towards increasing solubilities when $\mathrm{CO}_{2}$ is present, in comparison to solubility data for the binary (propane + water). The theory, however, predicts the opposite trend when the calculations for the ternary and the binary are compared at each temperature. It was already mentioned in the previous section that for (propane + water) the interaction parameters were selected based 
on enhancing also the predictions of the water-rich phase; as said this was done at the expense of a loss in accuracy in the predictions of the alkane-rich phase. If the interaction parameters that reproduce best the alkane-rich phase $\left(k_{i j}=0.3006\right.$ and $\gamma_{i j}=0$, instead of the $k_{i j}=-0.99$ and $\gamma_{i j}=0.2225$ set $)$ are used in the calculations of the ternary phase behaviour, the solubility of water in the alkane-rich phase is predicted to increase upon the addition of carbon dioxide with respect to that of the binary (calculated with the same interaction parameters), in agreement with the trend found experimentally. Experimentally however, measuring the water content of this phase is not exempt of difficulty, as discussed in previous work [4]. It can be concluded that carbon dioxide may act as a mild co-solvent on the mutual solubilities of (propane + water) although such findings are not supported by the theoretical approach in the aqueous phase.

\subsection{Influence of propane on the phase behaviour of (carbon dioxide + water)}

The influence of propane on the mutual solubility of (carbon dioxide + water) is studied by comparison to binary data for (carbon dioxide + water), where we study the carbon dioxide-rich and the water-rich phases separately. Regarding, first, the carbon dioxide-rich phase, a trend towards decreasing the solubility of water when propane is present can be seen in Figure 11. The predictions of the theory are consistent with the experimental findings. It is interesting to note that this anti-solvent effect of the alkane over the mutual solubilities of carbon dioxide and water was not observed with the ternary containing $n$-decane [4]. This behaviour may be attributed to the higher alkane content of the carbon dioxide-rich phase in the ternary system based on propane compared to that present in the system based on decane.

In the water-rich phase the addition of propane leads to a notable decrease in the saturated compositions of carbon dioxide, compared to the binary. This can be seen in Figure 12, where the isotherms for the ternary are plotted against one isotherm for the binary at the temperature closest to the lowest studied in this work; at higher temperatures the same effect could be seen, although the comparison is not plotted in the graph for sake of clarity. This anti-solvent effect of propane on the water-rich phase is seen to commence at low pressure, so that below the vapour pressure of propane the amount of carbon dioxide in water is negligible and nearly independent of pressure; the slope then changes for pressures higher than the vapour pressure of propane. This noticeable effect is quite surprising given the low solubility of propane in the water phase, but it is justified based on chemical potentials; i.e., it is related to the high solubility of propane in the coexisting carbon dioxide-rich phase. Comparing to the findings of our previous work [4], the addition of decane presented a very mild effect, only visible at high pressure (close to the upper critical end points; i.e., pressures $>10 \mathrm{MPa}$ ). In Figure 13, we examine the solubility of carbon dioxide in the water phase of a different ternary system, this time (methane + carbon dioxide + water) [12], again compared to solubility data in the aqueous phase of the binary (carbon dioxide + water). As in the case of propane, the antisolvent effect of a light hydrocarbon, now methane, can be observed in this figure. Because in this case the data for this ternary are in the two phase region, the solubility of carbon dioxide in water depends on 
the methane content of the gaseous $\mathrm{CO}_{2}$-rich phase; it is clear how the solubility decreases as the methane content increases (see Figure 13), in agreement with our earlier reasoning. In Figure 13 the data for both the (propane + carbon dioxide + water $)$ measured here and the $($ decane + carbon dioxide + water) system presented earlier [4] are also plotted at the same temperature for completeness; the effect of $n$-decane at this temperature is negligible.

Concerning reservoir processing, one of the roles of $\mathrm{CO}_{2}$ in EOR is that of reducing the interfacial tension between the oil and the water by dissolution [97], hence promoting the coalescence of the drops of oil that were trapped after secondary oil recovery. The notable decrease observed in the solubility of carbon dioxide in the water-rich phase when in the presence of a light hydrocarbon suggests that the properties of the aqueous phase would be even closer to those of pure water. On the other hand, if the solubility of carbon dioxide in the alkane-rich phase is analysed for the two cases studied of propane and decane at a temperature of, for example, $323 \mathrm{~K}$ and pressures below the upper critical end point, it can be seen that less $\mathrm{CO}_{2}$ is dissolved in the propane-rich phase, compared to the decane-rich one. It could then be thought that the performance of $\mathrm{CO}_{2}$ in enhanced oil recovery is less efficient in the case of low-molecular weight hydrocarbons, where less carbon dioxide dissolves in the aqueous and the oil phase. This is in practice not a drawback, given the easier recovery of light fractions of oil because of their high volatility and the low pressure necessary to achieve conditions of total miscibility with the injected $\mathrm{CO}_{2}$ (i.e., above the upper critical end point of these components with carbon dioxide at a given temperature). The discussion can also be extended to the topic of sequestration of $\mathrm{CO}_{2}$ in the reservoir; if only the solubility trapping in the reservoir water is considered, it will be enhanced if the injected carbon dioxide is free of volatile alkanes. To conclude this section, it can be said that propane is observed to act as an anti-solvent on the mutual solubilities of (carbon dioxide + water).

\section{Conclusions}

The phase behaviour of the system (propane + carbon dioxide + water) has been studied both experimentally and theoretically, and compared in detail to the ternary mixture of $(n$-decane + carbon dioxide + water) presented in previous work [4]. Experimentally, the VLLE of the system (propane + carbon dioxide + water) has been measured along four isotherms from $T=(311.10$ to 353.18$) \mathrm{K}$ and pressures ranging from values above the vapour pressure of propane $p=(1.67$ to 3.71) $\mathrm{MPa}$ to the upper critical end point between the carbon dioxide-rich and the propane-rich phases in the presence of the water-rich phase, these latter found to range from $p=(6.71$ to 5.51$) \mathrm{MPa}$ with increasing temperatures. The analysis of the system has been complemented with calculations performed with the SAFT-VR equation. Details of the models used to describe the thermodynamic properties of these fluids and their mixtures have been given. Because a classical equation is used, with a given set of intermolecular potential parameters it is not possible to predict 
accurately and simultaneously the phase behaviour at conditions both far from and close to criticality. The parameters need therefore to be adjusted either at low temperature or at near critical conditions, where the latter strategy is typically followed with cubic equations of state. In a similar manner, here the intermolecular potential parameters for the most volatile components (i.e., carbon dioxide and propane) have been re-scaled to the experimental critical point. Where possible, the behaviour of the binary subsystems have been predicted and in all cases, temperature- and phase-independent binary interaction parameters have been used.

The experimental VLLE data for the ternary system (propane + carbon dioxide + water) have been compared to literature data for the corresponding binary subsystems, as well as to the phase equilibria predicted with SAFT-VR and to the observations that were earlier made in the previous study on (decane + carbon dioxide + water) [4]. Overall, the comparison between the mutual solubilities of the three components at conditions of three phase equilibria for the ternary system and the solubility of the components in the corresponding binary subsystems shows only small differences. The solubility of water in propane and that of propane in water seem to increase slightly with respect to the binary (propane + water) when $\mathrm{CO}_{2}$ is present, although the reversed effect is seen with the theory on the water-rich side. The mutual solubilities of carbon dioxide and water decrease notably in presence of propane, compared to the binary system (carbon dioxide + water). A similar comparison with the binary (propane + carbon dioxide) system shows no appreciable differences, probably due to the relatively low pressures of study.

\section{Acknowledgement}

The authors gratefully acknowledge the financial support of Shell International Exploration and Production B.V. in sponsoring this project and further support from EPSRC (Grant no. EP/E016340/1) to the Molecular Systems Engineering group. We also thank Andrew J. Haslam for help with Hudson and McCoubrey calculations.

\section{References}

[1] M. A. McHugh, V. J. Krukonis, Supercritical Fluid Extraction, Elsevier, 1994.

[2] A. V. Kane, Performance Review of a Large-Scale CO2-WAG Enhanced Recovery Project, SACROC Unit Kelly-Snyder Field, J. Petrol. Tech. 31 (2) (1979) 217-231.

[3] M. V. Langston, S. F. Hoadley, D. N. Young, Definitive $\mathrm{CO}_{2}$ Flooding Response in the SACROC Unit, SPE Enhanced Oil Recovery Symposium, Tulsa, Oklahoma, 1988.

[4] E. Forte, A. Galindo, J. P. M. Trusler, Experimental and Molecular Modeling Study of the Three-Phase Behavior of (n-Decane + Carbon Dioxide + Water) at Reservoir Conditions, J. Phys. Chem. B 115 (49) (2011) 14591-14609.

[5] F. J. Fayers, R. I. Hawes, J. D. Mathews, Some Aspects of the Potential Application of Surfactants or CO2 as EOR Processes in North Sea Reservoirs, J. Petrol. Tech. 33 (9) (1981) 1617-1627. 
[6] E. P. Langston, J. A. Shirer, Performance of Jay/LEC Fields Unit Under Mature Waterflood and Early Tertiary Operations, J. Petrol. Tech. 37 (2) (1985) 261-268.

[7] M. Blunt, F. J. Fayers, F. M. Orr Jr., Carbon dioxide in enhanced oil recovery, Energy Convers. and Mgmt. 34 (9-11) (1993) 1197 - 1204, proceedings of the International Energy Agency Carbon Dioxide Disposal Symposium.

[8] F. Gozalpour, S. R. Ren, B. Tohidi, $\mathrm{CO}_{2}$ EOR and Storage in Oil Reservoirs, Oil Gas Sci. Technol. 60 (3) (2005) $537-546$.

[9] N. R. Nagarajan, M. M. Honarpour, K. Sampath, Reservoir-Fluid Sampling and Characterization Key to Efficient Reservoir Management, SPE / Abu Dhabi International Petroleum Exhibition and Conference, Abu Dhabi, UAE, 2007.

[10] B. Metz, O. Davidson, H. de Coninck, M. Loos, L. Meyer (Eds.), Carbon Dioxide Capture and Storage, Cambridge University Press, Cambridge, report, 2005.

[11] G. Brunner, J. Teich, R. Dohrn, Phase equilibria in systems containing hydrogen, carbon dioxide, water and hydrocarbons, Fluid Phase Equilib. 100 (1994) 253-268.

[12] J. Qin, R. J. Rosenbauer, Z. Duan, Experimental Measurements of Vapor-Liquid Equilibria of the H2O + CO2 + CH4 Ternary System, J. Chem. Eng. Data 53 (6) (2008) 1246-1249.

[13] C. Jarne, S. T. Blanco, M. A. Gallardo, E. Rauzy, S. Otìn, I. Velasco, Dew Points of Ternary Methane (or Ethane) + Carbon Dioxide + Water Mixtures: Measurement and Correlation, Energy Fuels 18 (2) (2004) 396-404.

[14] A. Dhima, J.-C. de Hemptinne, J. Jose, Solubility of Hydrocarbons and CO2 Mixtures in Water under High Pressure, Ind. Eng. Chem. Res. 38 (8) (1999) 3144-3161.

[15] K. Y. Song, R. Kobayashi, The water content of a carbon dioxide-rich gas mixture containing 5.31 Mol \% methane along the three-phase and supercritical conditions, J. Chem. Eng. Data 35 (3) (1990) 320-322.

[16] V. Belandria, A. Eslamimanesh, A. H. Mohammadi, P. Theveneau, H. Legendre, D. Richon, Compositional Analysis and Hydrate Dissociation Conditions Measurements for Carbon Dioxide + Methane + Water System, Ind. Eng. Chem. Res. 50 (9) (2011) 5783-5794.

[17] Y. Zhang, G. D. Holder, R. P. Warzinski, Phase Equilibrium in Two-Phase, Water-Rich-Liquid, Hydrate Systems: Experiment and Theory, Ind. Eng. Chem. Res. 47 (2) (2008) 459-469.

[18] J. G. Beltràn, P. Servio, Equilibrium Studies for the System Methane + Carbon Dioxide + Neohexane + Water, J. Chem. Eng. Data 53 (8) (2008) 1745-1749.

[19] Y.-T. Seo, H. Lee, J.-H. Yoon, Hydrate Phase Equilibria of the Carbon Dioxide, Methane, and Water System, J. Chem. Eng. Data 46 (2) (2001) 381-384.

[20] L. Gil, S. Avila, P. García-Giménez, S. T. Blanco, C. Berro, S. Otin, I. Velasco, Dew Points of Binary Propane or n-butane + Carbon Dioxide, Ternary Propane or n-butane + Carbon Dioxide + Water, and Quaternary Propane or n-butane + Carbon Dioxide + Water + Methanol Mixtures: Measurement and Modeling, Ind. Eng. Chem. Res. 45 (11) (2006) 3974-3980.

[21] D. B. Robinson, B. R. Mehta, Hydrates in the propane-carbon dioxide-water system, J. Can. Pet. Technol. 48 (1971) $642-644$.

[22] R. D. Craig, Four-Phase Equilibria in the Gas-Hydrate System: Carbon Dioxide - Propane - Water, Ph.D. thesis, 1972.

[23] R. L. Scott, P. H. van Konynenburg, Static properties of solutions. Van der Waals and related models for hydrocarbon mixtures, Discuss. Faraday Soc. 49 (1970) 87-97.

[24] P. H. van Konynenburg, R. L. Scott, Critical Lines and Phase Equilibria in Binary Van Der Waals Mixtures, Philos. Trans. R. Soc. London 298 (1442) (1980) 495-540.

[25] L. W. Diamond, N. N. Akinfiev, Solubility of CO2 in water from -1.5 to $100{ }^{\circ} \mathrm{C}$ and from 0.1 to $100 \mathrm{MPa}$ : evaluation of literature data and thermodynamic modelling, Fluid Phase Equilib. 208 (1-2) (2003) 265 - 290.

[26] N. Spycher, K. Pruess, J. Ennis-King, CO2-H2O mixtures in the geological sequestration of CO2. I. Assessment and calculation of mutual solubilities from 12 to $100^{\circ} \mathrm{C}$ and up to 600 bar, Geochim. Cosmochim. Acta 67 (16) (2003) 3015 
$-3031$.

[27] C. Tsonopoulos, G. M. Wilson, High-temperature mutual solubilities of hydrocarbons and water .1. Benzene, Cyclohexane and normal-hexane, AIChE J. 29 (6) (1983) 990-999.

[28] J. L. Heidman, C. Tsonopoulos, C. J. Brady, G. M. Wilson, High-temperature mutual solubilities of hydrocarbons and water .2. Ethylbenzene, ethylcyclohexane, and normal-octane, AIChE J. 31 (3) (1985) 376

[29] I. G. Economou, J. L. Heidman, C. Tsonopoulos, G. M. Wilson, Mutual solubilities of hydrocarbons and water: III. 1-hexene; 1-octene; $\mathrm{C}_{1} 0-\mathrm{C}_{1} 2$ hydrocarbons, AIChE J. 43 (2) (1997) 535-546.

[30] C. Tsonopoulos, Thermodynamic analysis of the mutual solubilities of normal alkanes and water, Fluid Phase Equilib. $156(1-2)(1999)$ 21-33.

[31] C. Tsonopoulos, Thermodynamic analysis of the mutual solubilities of hydrocarbons and water, Fluid Phase Equilib. 186 (1-2) (2001) 185-206.

[32] A. Maczynski, D. G. Shaw, M. Goral, B. Wisniewska-Goclowska, A. Skrzecz, Z. Maczynska, I. Owczarek, K. Blazej, M.-C. Haulait-Pirson, F. Kapuku, G. T. Hefter, A. Szafranski, IUPAC-NIST Solubility Data Series. 81. Hydrocarbons with Water and Seawater. Revised and Updated Part 1. C5 Hydrocarbons with Water, J. Phys. Chem. Ref. Data 34 (2) (2005) 441-476.

[33] A. Maczynski, D. G. Shaw, M. Goral, B. Wisniewska-Goclowska, A. Skrzecz, I. Owczarek, K. Blazej, M.-C. HaulaitPirson, G. T. Hefter, F. Kapuku, Z. Maczynska, A. Szafranski, C. L. Young, IUPAC-NIST Solubility Data Series. 81. Hydrocarbons with Water and Seawater. Revised and Updated. Part 4. C6H14 Hydrocarbons with Water, J. Phys. Chem. Ref. Data 34 (2) (2005) 709-753.

[34] A. Maczynski, D. G. Shaw, M. Goral, B. Wisniewska-Goclowska, A. Skrzecz, I. Owczarek, K. Blazej, M.-C. HaulaitPirson, G. T. Hefter, F. Kapuku, Z. Maczynska, A. Szafranski, C. L. Young, IUPAC-NIST Solubility Data Series. 81. Hydrocarbons with Water and Seawater-Revised and Updated. Part 5. C7 Hydrocarbons with Water and Heavy Water, J. Phys. Chem. Ref. Data 34 (3) (2005) 1399-1487.

[35] D. G. Shaw, A. Maczynski, M. Goral, B. Wisniewska-Goclowska, A. Skrzecz, I. Owczarek, K. Blazej, M.-C. HaulaitPirson, G. T. Hefter, F. Kapuku, Z. Maczynska, A. Szafranski, IUPAC-NIST Solubility Data Series. 81. Hydrocarbons with Water and Seawater. Revised and Updated. Part 7. C8H12-C8H18 Hydrocarbons with Water, J. Phys. Chem. Ref. Data 34 (4) (2005) 2261-2298.

[36] D. G. Shaw, A. Maczynski, M. Goral, B. Wisniewska-Goclowska, A. Skrzecz, I. Owczarek, K. Blazej, M.-C. HaulaitPirson, G. T. Hefter, F. Kapuku, Z. Maczynska, A. Szafranski, IUPAC-NIST Solubility Data Series. 81. Hydrocarbons with Water and Seawater. Revised and Updated. Part 8. C9 Hydrocarbons with Water, J. Phys. Chem. Ref. Data 34 (4) (2005) 2299-2345.

[37] D. G. Shaw, A. Maczynski, M. Goral, B. Wisniewska-Goclowska, A. Skrzecz, I. Owczarek, K. Blazej, M.-C. HaulaitPirson, G. T. Hefter, F. Kapuku, Z. Maczynska, A. Szafranski, IUPAC-NIST Solubility Data Series. 81. Hydrocarbons with Water and Seawater. Revised and Updated. Part 9. C10 Hydrocarbons with Water, J. Phys. Chem. Ref. Data 35 (1) (2006) 93-151.

[38] D. G. Shaw, A. Maczynski, M. Goral, B. Wisniewska-Goclowska, A. Skrzecz, I. Owczarek, K. Blazej, M.-C. HaulaitPirson, G. T. Hefter, F. Kapuku, Z. Maczynska, A. Szafranski, IUPAC-NIST Solubility Data Series. 81. Hydrocarbons with Water and Seawater. Revised and Updated. Part 10. C11 and C12 Hydrocarbons with Water, J. Phys. Chem. Ref. Data 35 (1) (2006) 153-203.

[39] D. G. Shaw, A. Maczynski, M. Goral, B. Wisniewska-Goclowska, A. Skrzecz, I. Owczarek, K. Blazej, M.-C. HaulaitPirson, G. T. Hefter, F. Kapuku, Z. Maczynska, A. Szafranski, IUPAC-NIST Solubility Data Series. 81. Hydrocarbons with Water and Seawater.Revised and Updated. Part 11. C13-C36 Hydrocarbons with Water, J. Phys. Chem. Ref. Data 35 (2) (2006) 687-784. 
[40] D. G. Shaw, A. Maczynski, G. T. Hefter, M. Kleinschmidt, D. Mackay, P. A. Meyers, H. Miyamoto, W. Y. Shiu, IUPAC-NIST Solubility Data Series. 81. Hydrocarbons with Water and Seawater. Revised and Updated Part 12. C5-C26 Hydrocarbons with Seawater, J. Phys. Chem. Ref. Data 35 (2) (2006) 785-838.

[41] F. H. Poettman, M. R. Dean, Water Content of Propane, Petr. Ref. 25 (1946) 125-128.

[42] R. Kobayashi, D. Katz, Vapor-Liquid Equilibria For Binary Hydrocarbon-Water Systems, Ind. Eng. Chem. 45 (2) (1953) 440-446.

[43] M. Sánchez, R. Coll, System Propane - Water at Elevated Pressures and Temperatures. I. Two-Phase Region, An. Quim. 74 (1978) 1329-1335.

[44] S. T. Blanco, I. Velasco, E. Rauzy, S. Otín, Water dew points of binary nitrogen+water and propane+water mixtures. Measurement and correlation, Fluid Phase Equilib. 161 (1) (1999) 107-117.

[45] K. Y. Song, R. Kobayashi, The water content of ethane, propane and their mixtures in equilibrium with liquid water or hydrates, Fluid Phase Equilib. 95 (1994) 281-298.

[46] A. Chapoy, S. Mokraoui, A. Valtz, D. Richon, A. H. Mohammadi, B. Tohidi, Solubility measurement and modeling for the system propane-water from 277.62 to 368.16 K, Fluid Phase Equilib. 226 (0) (2004) 213 - 220.

[47] S. Mokraoui, C. Coquelet, A. Valtz, P. E. Hegel, D. Richon, New Solubility Data of Hydrocarbons in Water and Modeling Concerning Vapor-Liquid-Liquid Binary Systems, Ind. Eng. Chem. Res. 46 (26) (2007) 9257-9262.

[48] E. D. Sloan, K. A. Sparks, J. J. Johnson, Two-phase liquid hydrocarbon-hydrate equilibrium for ethane and propane, Ind. Eng. Chem. Res. 26 (6) (1987) 1173-1179.

[49] K. Y. Song, M. Yarrison, W. Chapman, Experimental low temperature water content in gaseous methane, liquid ethane, and liquid propane in equilibrium with hydrate at cryogenic conditions, Fluid Phase Equilib. 224 (2) (2004) 271-277.

[50] E. Brunner, Fluid mixtures at high pressures IX. Phase separation and critical phenomena in 23 (n-alkane + water) mixtures, J. Chem. Thermodyn. 22 (4) (1990) 335-353.

[51] T. W. de Loos, A. J. M. Wijen, G. A. M. Diepen, Phase equilibria and critical phenomena in fluid (propane + water) at high pressures and temperatures, J. Chem. Thermodyn. 12 (2) (1980) 193-204.

[52] W. G. Chapman, K. E. Gubbins, G. Jackson, M. Radosz, SAFT: Equation-of-state solution model for associating fluids, Fluid Phase Equilib. 52 (1989) 31-38.

[53] W. G. Chapman, K. E. Gubbins, G. Jackson, M. Radosz, New reference equation of state for associating liquids, Ind. Eng. Chem. Res. 29 (8) (1990) 1709-1721.

[54] A. Galindo, P. J. Whitehead, G. Jackson, A. N. Burgess, Predicting the High-Pressure Phase Equilibria of Water + n-Alkanes Using a Simplified SAFT Theory with Transferable Intermolecular Interaction Parameters, J. Phys. Chem. 100 (16) (1996) 6781-6792.

[55] I. V. Yakoumis, G. M. Kontogeorgis, E. C. Voutsas, E. M. Hendriks, D. P. Tassios, Prediction of Phase Equilibria in Binary Aqueous Systems Containing Alkanes, Cycloalkanes, and Alkenes with the Cubic-plus-Association Equation of State, Ind. Eng. Chem. Res. 37 (10) (1998) 4175-4182.

[56] E. C. Voutsas, G. C. Boulougouris, I. G. Economou, D. P. Tassios, Water/Hydrocarbon Phase Equilibria Using the Thermodynamic Perturbation Theory, Ind. Eng. Chem. Res. 39 (3) (2000) 797-804.

[57] B. H. Patel, P. Paricaud, A. Galindo, G. C. Maitland, Prediction of the Salting-Out Effect of Strong Electrolytes on Water Alkane Solutions, Ind. Eng. Chem. Res. 42 (16) (2003) 3809-3823.

[58] X.-S. Li, P. Englezos, Vapor-liquid equilibrium of systems containing alcohols, water, carbon dioxide and hydrocarbons using SAFT, Fluid Phase Equilib. 224 (1) (2004) 111 - 118.

[59] E. K. Karakatsani, G. M. Kontogeorgis, I. G. Economou, Evaluation of the Truncated Perturbed Chain-Polar Statistical Associating Fluid Theory for Complex Mixture Fluid Phase Equilibria, Ind. Eng. Chem. Res. 45 (17) (2006) 6063-6074.

[60] M. B. Oliveira, J. A. P. Coutinho, A. J. Queimada, Mutual solubilities of hydrocarbons and water with the CPA EoS, 
Fluid Phase Equilib. 258 (1) (2007) 58 - 66.

[61] S. Aparicio-Martínez, K. R. Hall, Phase equilibria in water containing binary systems from molecular based equations of state, Fluid Phase Equilib. 254 (1-2) (2007) 112 - 125.

[62] L. F. Vega, F. Llovell, F. J. Blas, Capturing the Solubility Minima of n-Alkanes in Water by Soft-SAFT, J. Phys. Chem. B 113 (21) (2009) 7621-7630.

[63] D. Nguyen-Huynh, J.-C. de Hemptinne, R. Lugo, J.-P. Passarello, P. Tobaly, Modeling Liquid-Liquid and Liquid-Vapor Equilibria of Binary Systems Containing Water with an Alkane, an Aromatic Hydrocarbon, an Alcohol or a Gas (Methane, Ethane, CO2 or H2S), Using Group Contribution Polar Perturbed-Chain Statistical Associating Fluid Theory, Ind. Eng. Chem. Res. 50 (12) (2011) 7467-7483.

[64] C. P. Emborsky, K. R. Cox, W. G. Chapman, Correlation and Prediction of Water Content in Alkanes Using a Molecular Theory, Ind. Eng. Chem. Res. 50 (13) (2011) 7791-7799.

[65] V. Papaioannou, C. S. Adjiman, G. Jackson, A. Galindo, Simultaneous prediction of vapour-liquid and liquid-liquid equilibria (VLE and LLE) of aqueous mixtures with the SAFT- $\gamma$ group contribution approach, Fluid Phase Equilib. 306 (1) (2011) 82 - 96, 20 years of the SAFT equation of state - Recent advances and challenges, Symposium.

[66] A. Valtz, A. Chapoy, C. Coquelet, P. Paricaud, D. Richon, Vapour-liquid equilibria in the carbon dioxide-water system, measurement and modelling from 278.2 to 318.2 K, Fluid Phase Equilib. 226 (2004) 333-344.

[67] G. M. Kontogeorgis, M. L. Michelsen, G. K. Folas, S. Derawi, N. von Solms, E. H. Stenby, Ten Years with the CPA (Cubic-Plus-Association) Equation of State. Part 2. Cross-Associating and Multicomponent Systems, Ind. Eng. Chem. Res. 45 (14) (2006) 4869-4878.

[68] M. C. dos Ramos, F. J. Blas, A. Galindo, Modelling the phase equilibria and excess properties of the water carbon dioxide binary mixture, Fluid Phase Equilib. 261 (1-2) (2007) 359-365.

[69] M. C. dos Ramos, F. J. Blas, A. Galindo, Phase Equilibria, Excess Properties, and Henry's Constants of the Water Carbon Dioxide Binary Mixture, J. Phys. Chem. C 111 (43) (2007) 15924-15934.

[70] G. M. Kontogeorgis, G. K. Folas, N. Muro-Suñé, F. Roca Leon, M. L. Michelsen, Les théories d'association et le phénomène de la solvatation : application aux industries du pétrole et du gaz, et à la pétrochimie, OGST - Rev. IFP 63 (3) (2008) 305-319.

[71] N. Mac Dowell, F. Llovell, C. S. Adjiman, G. Jackson, A. Galindo, Modeling the Fluid Phase Behavior of Carbon Dioxide in Aqueous Solutions of Monoethanolamine Using Transferable Parameters with the SAFT-VR Approach, Ind. Eng. Chem. Res. 49 (4) (2010) 1883-1899.

[72] J. M. Míguez, M. C. dos Ramos, M. M. Piñeiro, F. J. Blas, An Examination of the Ternary Methane + Carbon Dioxide + Water Phase Diagram using the SAFT-VR Approach, J. Phys. Chem. B 115 (31) (2011) 9604-9617.

[73] G. M. Kontogeorgis, I. Tsivintzelis, M. L. Michelsen, E. H. Stenby, Towards predictive association theories, Fluid Phase Equilib. 301 (2) (2011) $244-256$.

[74] A. Gil-Villegas, A. Galindo, P. J. Whitehead, S. J. Mills, G. Jackson, A. N. Burgess, Statistical associating fluid theory for chain molecules with attractive potentials of variable range, J. Chem. Phys. 106 (10) (1997) 4168-4186.

[75] A. Galindo, L. A. Davies, A. Gil-Villegas, G. Jackson, The thermodynamics of mixtures and the corresponding mixing rules in the SAFT-VR approach for potentials of variable range, Mol. Phys. 93 (2) (1998) 241-252.

[76] F. J. Blas, A. Galindo, Study of the high pressure phase behaviour of $\mathrm{CO}_{2}+\mathrm{n}$-alkane mixtures using the SAFT-VR approach with transferable parameters, Fluid Phase Equilib. 194-197 (2002) 501-509.

[77] A. Galindo, F. J. Blas, Theoretical Examination of the Global Fluid Phase Behavior and Critical Phenomena in Carbon Dioxide + n-Alkane Binary Mixtures, J. Phys. Chem. B 106 (17) (2002) 4503-4515.

[78] S. Dufal, A. Galindo, G. Jackson, A. J. Haslam, Modelling the effect of methanol, glycol inhibitors and electrolytes on the equilibrium stability of hydrates with the SAFT-VR approach, Mol. Phys. 110 (11-12) (2012) 1223-1240. 
[79] B. N. Taylor, C. E. Kuyatt, Guidelines for Evaluating and Expressing the Uncertainty of NIST Measurement Results, NIST Technical Note 1297, National Institute of Standards and Technology, Physics Laboratory, Gaithersburg, MD, 1993.

[80] C. McCabe, A. Galindo, A. Gil-Villegas, G. Jackson, Predicting the High-Pressure Phase Equilibria of Binary Mixtures of Perfluoro-n-alkanes + n-Alkanes Using the SAFT-VR Approach, J. Phys. Chem. B 102 (41) (1998) 8060-8069.

[81] C. McCabe, G. Jackson, SAFT-VR modelling of the phase equilibrium of long-chain n-alkanes, Phys. Chem. Chem. Phys. 1 (1999) 2057-2064.

[82] P. Paricaud, A. Galindo, G. Jackson, Modeling the Cloud Curves and the Solubility of Gases in Amorphous and Semicrystalline Polyethylene with the SAFT-VR Approach and Flory Theory of Crystallization, Ind. Eng. Chem. Res. 43 (21) (2004) 6871-6889.

[83] G. N. I. Clark, A. J. Haslam, A. Galindo, G. Jackson, Developing optimal Wertheim-like models of water for use in Statistical Associating Fluid Theory (SAFT) and related approaches, Mol. Phys. 104 (22-24) (2006) 3561-3581.

[84] C. McCabe, S. B. Kiselev, A crossover SAFT-VR equation of state for pure fluids: preliminary results for light hydrocarbons, Fluid Phase Equilib. 219 (1) (2004) 3 - 9.

[85] C. McCabe, S. B. Kiselev, Application of Crossover Theory to the SAFT-VR Equation of State: SAFT-VRX for Pure Fluids, Ind. Eng. Chem. Res. 43 (11) (2004) 2839-2851.

[86] L. Sun, H. Zhao, S. B. Kiselev, C. McCabe, Predicting Mixture Phase Equilibria and Critical Behavior Using the SAFTVRX Approach, J. Phys. Chem. B 109 (18) (2005) 9047-9058.

[87] L. Sun, H. Zhao, S. B. Kiselev, C. McCabe, Application of SAFTÜVRX to binary phase behaviour: alkanes, Fluid Phase Equilib. 228-229 (0) (2005) 275-282.

[88] E. Forte, F. Llovell, L. F. Vega, J. P. M. Trusler, A. Galindo, Application of a renormalization-group treatment to the statistical associating fluid theory for potentials of variable range (SAFT-VR), J. Chem. Phys. 134 (15) 154102.

[89] E. Forte, F. Llovell, J. P. M. Trusler, A. Galindo, Application of the statistical associating fluid theory for potentials of variable range (SAFT-VR) coupled with renormalisation-group (RG) theory to model the phase equilibria and secondderivative properties of pure fluids, Fluid Phase Equilib. 0 (0) (2012) 0, in press.

[90] A. J. Haslam, A. Galindo, G. Jackson, Prediction of binary intermolecular potential parameters for use in modelling fluid mixtures, Fluid Phase Equilib. 266 (1-2) (2008) 105-128.

[91] A. D. Buckingham, Electric moments of molecules, in: H. Eyring, D. Henderson, W. Jost (Eds.), Physical Chemistry: An Advanced Treatise, Vol. 4, Molecular properties, chap. 8, Academic Press, New York/London, 1970.

[92] D. R. Lide, CRC Handbook of Chemistry and Physics, CRC Press/Taylor and Francis, Boca Raton, 86th edn., 2005.

[93] J. A. Briones, J. C. Mullins, M. C. Thies, B. U. Kim, Ternary phase equilibria for acetic acid-water mixtures with supercritical carbon dioxide, Fluid Phase Equilib. 36 (1987) 235 - 246, ISSN 0378-3812.

[94] R. Wiebe, V. L. Gaddy, The Solubility in Water of Carbon Dioxide at 50, 75 and 100 C, at Pressures to 700 Atmospheres, J. Am. Chem. Soc. 61 (2) (1939) 315-318.

[95] R. Wiebe, V. L. Gaddy, Vapor Phase Composition of Carbon Dioxide-Water Mixtures at Various Temperatures and at Pressures to 700 Atmospheres, J. Am. Chem. Soc. 63 (2) (1941) 475-477.

[96] M. Bluma, U. K. Deiters, A classification of phase diagrams of ternary fluid systems, Phys. Chem. Chem. Phys. 1 (18) (1999) 4307.

[97] A. Georgiadis, G. Maitland, J. P. M. Trusler, A. Bismarck, Interfacial Tension Measurements of the (H2O + n-Decane + CO2) Ternary System at Elevated Pressures and Temperatures, J. Chem. Eng. Data 56 (12) (2011) 4900-4908.

[98] J. H. Kim, M. S. Kim, Vapor-liquid equilibria for the carbon dioxide + propane system over a temperature range from 253.15 to 323.15 K, Fluid Phase Equilib. 238 (1) (2005) 13-19.

[99] V. G. Niesen, J. C. Rainwater, Critical locus, (vapor + liquid) equilibria, and coexisting densities of (carbon dioxide + 
propane) at temperatures from $311 \mathrm{~K}$ to $361 \mathrm{~K}$, J. Chem. Thermodyn. 22 (8) (1990) 777-795.

[100] B. D. Smith, R. Srivastava, Thermodynamic data for pure compounds part A: Hydrocarbons and Ketones, Elsevier, Amsterdam, 1986.

[101] O. Sifner, F. Nemec, Vapor pressure and saturated liquid density of seven hydrocarbons, Chem. Prum. 36 (8) (1986) $420-423$.

[102] J. M. Sengers, H. Levelt, W. T. Chen, Vapor Pressure, Critical Isochore and Some Metastable States of Carbon Dioxide, J. Chem. Phys. 56 (0021-9606) (1972) 595-608.

[103] C. F. Jenkin, D. R. Pye, The thermal properties of carbonic acid at low temperatures, Philos. Trans. R. Soc. London Ser. A 213 (0962-8428) (1914) 67.

[104] C. H. Meyers, M. S. van Dusen, The vapor pressure of liquid and solid carbon dioxide, Bur. Stand. J. Res. 10 (0091-1801) (1933) 381-412.

[105] L. A. Webster, A. J. Kidnay, Vapor-liquid equilibria for the methane-propane-carbon dioxide systems at $230 \mathrm{~K}$ and 270 K, J. Chem. Eng. Data 46 (3) (2001) 759-764.

[106] V. G. Matvienko, N. L. Yarym-Agaev, Vapor-liquid equilibrium and volumetric properties of the liquid phase of the gamma-butyrolactone-carbon dioxide system at increasing pressures, Zh. Prikl. Khim. 72 (7) (1999) 1085-1089.

[107] P. Nowak, T. Tielkes, R. Kleinrahm, W. Wagner, Supplementary measurements of the (p,rho,T) relation of carbon dioxide in the homogeneous region at $\mathrm{T}=313 \mathrm{~K}$ and on the coexistence curve at $\mathrm{T}=304 \mathrm{~K}$, J. Chem. Thermodyn. 29 (8) (1997) 885-889.

[108] J. G. Roof, J. D. Baron, Critical loci of binary mixtures of propane with methane, carbon dioxide, and nitrogen, J. Chem. Eng. Data 12 (3) (1967) 292-293.

[109] G. Morrison, J. M. Kincaid, Critical Point Measurements on Nearly Polydisperse Fluids, AIChE J. 30 (2) (1984) $257-262$.

[110] F. Fogh, Experimental Determination of High Pressure Dew and Bubble Points Using a Microwave Technique, Ph.D. thesis, 1988.

[111] S. Horstmann, K. Fischer, J. Gmehling, The experimental determination of critical points of pure compounds and binary mixtures using a flow apparatus, Chem. Ing. Tech. 71 (1999) 725-728.

[112] L. J. V. Poolen, C. D. Holcomb, Critical temperatures, pressures, and densities for the mixtures CO2-C3H8, CO2-nC4H10, C2-C3H8, and C3H8-nC4H10, Fluid Phase Equilib. 165 (2) (1999) 157 - 168.

[113] J. Ke, M. W. George, M. Poliakoff, B. Han, H. Yan, How Does the Critical Point Change during the Hydrogenation of Propene in Supercritical Carbon Dioxide?, J. Phys. Chem. B 106 (17) (2002) 4496-4502.

[114] S. Umano, Y. Nakano, Solubilities of propane and n-butane in water and common-salt solution, Kogyo Kagaku Zasshi 61 (5) (1958) 536-542.

[115] N. Klausutis, Phase equilibrium in the propane - propylene - water system in the three - phase region, Ph.D. thesis, Austin, Texas, 1968.

[116] M. B. King, A. Mubarak, J. D. Kim, T. R. Bott, The Mutual Solubilities of Water with Supercritical and Liquid Carbon Dioxide, J. Supercrit. Fluids 5 (1992) 296-302.

[117] S. D. Zaalishvili, The solubility of carbon dioxide mixed with hydrogen and nitrogen in water under pressure, Zh. Fiz. Khim. 14 (1940) 413-417.

[118] H. H. Reamer, B. H. Sage, W. N. Lacey, Phase Equilibria in Hydrocarbon Systems. Volumetric and Phase Behavior of the Propane-Carbon Dioxide System, Ind. Eng. Chem. 43 (11) (1951) 2515-2520.

[119] F. H. Poettmann, D. L. Katz, Phase Behavior of Binary Carbon Dioxide-Paraffin Systems, Ind. Eng. Chem. 37 (9) (1945) $847-853$.

[120] C. R. Coan, A. D. King, Solubility of water in compressed carbon dioxide, nitrous oxide, and ethane. Evidence for hydration of carbon dioxide and nitrous oxide in the gas phase, J. Am. Chem. Soc. 93 (8) (1971) 1857-1862. 
[121] A. Bamberger, G. Sieder, G. Maurer, High-pressure (vapor-liquid) equilibrium in binary mixtures of (carbon dioxide + water or acetic acid) at temperatures from 313 to 353 K, J. Supercrit. Fluids 17 (2000) 97-110.

[122] I. P. Sidorov, Y. S. Kazarnovskii, A. M. Goldman, Solubility of water in compressed gases, Tr. GIAP (1) (1952) 48-67.

[123] J. Kiepe, S. Horstmann, K. Fischer, J. Gmehling, Experimental Determination and Prediction of Gas Solubility Data for $\mathrm{CO} 2$ + $\mathrm{H} 2 \mathrm{O}$ Mixtures Containing $\mathrm{NaCl}$ or $\mathrm{KCl}$ at Temperatures between 313 and $393 \mathrm{~K}$ and Pressures up to $10 \mathrm{MPa}$, Ind. Eng. Chem. Res. 41 (17) (2002) 4393-4398.

[124] G. Zhang, Y. Wu, P. Ma, G. Wu, D. Li, The Measurement and Correlation of Carbon Monoxide and Other Gases Solubility in Phenol, The First National Conference on Chemical and Biochemical Engineering, Nanjing, China, 1-7, 2004 .

[125] C. E. P. Siqueira Campos, H. G. D'Amato Villardi, F. L. Pellegrini Pessoa, A. M. Cohen Uller, Solubility of Carbon Dioxide in Water and Hexadecane: Experimental Measurement and Thermodynamic Modeling, J. Chem. Eng. Data 54 (10) (2009) 2881-2886.

[126] F. Gu, Solubility of Carbon Dioxide in Aqueous Sodium Chloride Solution under High Pressure, Gaoxiao Huaxue Gongcheng Xuebao 12 (1998) 118-123.

[127] A. Zawisza, B. Malesinska, Solubility of carbon dioxide in liquid water and of water in gaseous carbon dioxide in the range 0.2-5 MPa and at temperatures up to 473 K, J. Chem. Eng. Data 26 (4) (1981) 388-391.

[128] Y. D.Zelvenskii, The solubility of carbon dioxide under pressure, Zhurn. Khim. Prom. (J. Chem. Ind.) 14 (1937) 12501257. 
Table 1: GC conditions set for the analysis of the mixture studied in this work $^{a}$.

\begin{tabular}{|c|c|c|c|c|c|c|}
\hline \multicolumn{2}{|c|}{ Injector } & \multirow{2}{*}{$\frac{\text { Oven }}{T / \mathrm{K}}$} & \multicolumn{2}{|c|}{ TCD } & \multicolumn{2}{|c|}{ FID } \\
\hline$\dot{V} / \mathrm{cm}^{3} \cdot \mathrm{s}^{-1}$ & $T / \mathrm{K}$ & & $T / \mathrm{K}$ & $I / \mathrm{mA}$ & $T / \mathrm{K}$ & $\phi_{r}$ \\
\hline 40 & 473.15 & 373.15 & 503.15 & 90 & 503.15 & $1: 10$ \\
\hline
\end{tabular}

${ }^{a} \mathrm{TCD}=$ Thermal Conductivity Detector, FID $=$ Flame Ionisation Detector.

$\dot{V}=$ He flow rate, $I=$ current, $\phi_{r}=\mathrm{H}_{2}$ : Air flow ratio.

Table 2: Experimental VLLE data and SAFT-VR calculations for (propane (1) + carbon dioxide (2) + water (3)) where I, II and III denote the propane-rich, carbon dioxide-rich and water-rich phases, respectively.

\begin{tabular}{|c|c|c|c|c|c|c|c|c|}
\hline Phase & $p / \mathrm{MPa}$ & $x_{1}^{\exp }$ & $x_{2}^{\exp }$ & $x_{3}^{\exp }$ & $p / \mathrm{MPa}$ & $x_{1}^{\text {pred }}$ & $x_{2}^{\text {pred }}$ & $x_{3}^{\text {pred }}$ \\
\hline & \multicolumn{4}{|c|}{$T=311.10 \mathrm{~K}$} & \multicolumn{4}{|c|}{$T=311.10 \mathrm{~K}$} \\
\hline I & 1.67 & 0.9538 & 0.0394 & 0.0068 & 1.67 & 0.9580 & 0.0395 & 0.0026 \\
\hline II & 1.67 & 0.8045 & 0.1885 & 0.0070 & 1.67 & 0.8598 & 0.1362 & 0.0040 \\
\hline III & 1.67 & $3.5 \times 10^{-4}$ & 0.0015 & 0.9982 & 1.67 & $1.7 \times 10^{-4}$ & 0.0009 & 0.9989 \\
\hline I & 3.47 & 0.7313 & 0.2650 & 0.0037 & 3.48 & 0.6700 & 0.3274 & 0.0026 \\
\hline II & 3.48 & 0.4108 & 0.5855 & 0.0037 & 3.48 & 0.4204 & 0.5772 & 0.0024 \\
\hline III & 3.48 & $3.0 \times 10^{-4}$ & 0.0077 & 0.9920 & 3.48 & $1.3 \times 10^{-4}$ & 0.0073 & 0.9926 \\
\hline I & 4.97 & 0.5024 & 0.4928 & 0.0048 & 4.97 & 0.4369 & 0.5604 & 0.0027 \\
\hline II & 4.96 & 0.2905 & 0.7072 & 0.0024 & 4.97 & 0.2787 & 0.7192 & 0.0021 \\
\hline III & 4.98 & $2.7 \times 10^{-4}$ & 0.0126 & 0.9872 & 4.97 & $9.4 \times 10^{-5}$ & 0.0117 & 0.9882 \\
\hline I & 6.43 & 0.2671 & 0.7282 & 0.0047 & 6.43 & 0.2230 & 0.7744 & 0.0026 \\
\hline II & 6.44 & 0.2141 & 0.7838 & 0.0022 & 6.43 & 0.1817 & 0.8162 & 0.0021 \\
\hline \multirow[t]{2}{*}{ III } & 6.43 & $2.0 \times 10^{-4}$ & 0.0162 & 0.9836 & 6.43 & $6.0 \times 10^{-5}$ & 0.0156 & 0.9843 \\
\hline & \multicolumn{4}{|c|}{$T=323.01 \mathrm{~K}$} & \multicolumn{4}{|c|}{$T=323.01 \mathrm{~K}$} \\
\hline I & 1.86 & 0.9789 & 0.0135 & 0.0076 & 1.86 & 0.9925 & 0.0037 & 0.0038 \\
\hline II & 1.86 & 0.9445 & 0.0456 & 0.0098 & 1.86 & 0.9814 & 0.0123 & 0.0064 \\
\hline III & 1.86 & $4.3 \times 10^{-4}$ & 0.0005 & 0.9991 & 1.86 & $1.6 \times 10^{-4}$ & 0.0017 & 0.9998 \\
\hline
\end{tabular}


Table 2: Experimental VLLE data and SAFT-VR calculations for (propane $(1)+$ carbon dioxide $(2)+$ water (3)) (continued).

\begin{tabular}{|c|c|c|c|c|c|c|c|c|}
\hline Phase & $p / \mathrm{MPa}$ & $x_{1}^{\exp }$ & $x_{2}^{\exp }$ & $x_{3}^{\exp }$ & $p / \mathrm{MPa}$ & $x_{1}^{\text {pred }}$ & $x_{2}^{\text {pred }}$ & $x_{3}^{\text {pred }}$ \\
\hline I & 3.02 & 0.8605 & 0.1330 & 0.0066 & 3.02 & 0.8308 & 0.1653 & 0.0038 \\
\hline II & 3.02 & 0.6270 & 0.3677 & 0.0054 & 3.02 & 0.6365 & 0.3590 & 0.0045 \\
\hline III & 3.02 & $4.4 \times 10^{-4}$ & 0.0039 & 0.9956 & 3.02 & $1.4 \times 10^{-4}$ & 0.0058 & 0.9964 \\
\hline I & 4.44 & 0.6947 & 0.2990 & 0.0063 & 4.45 & 0.6344 & 0.3617 & 0.0038 \\
\hline II & 4.46 & 0.4618 & 0.5341 & 0.0041 & 4.45 & 0.4452 & 0.5512 & 0.0036 \\
\hline III & 4.45 & $3.2 \times 10^{-4}$ & 0.0077 & 0.9920 & 4.45 & $1.1 \times 10^{-4}$ & 0.0102 & 0.9927 \\
\hline I & 5.98 & 0.4899 & 0.5037 & 0.0064 & 5.99 & 0.4234 & 0.5729 & 0.0038 \\
\hline II & 6.00 & 0.3679 & 0.6283 & 0.0038 & 5.99 & 0.3371 & 0.6596 & 0.0033 \\
\hline \multirow[t]{2}{*}{ III } & 6.00 & $3.9 \times 10^{-4}$ & 0.0110 & 0.9886 & 5.99 & $7.1 \times 10^{-5}$ & 0.0145 & 0.9893 \\
\hline & \multicolumn{4}{|c|}{$T=338.10 \mathrm{~K}$} & \multicolumn{4}{|c|}{$T=338.10 \mathrm{~K}$} \\
\hline I & 2.60 & 0.9610 & 0.0205 & 0.0185 & 2.61 & 0.9766 & 0.0173 & 0.0061 \\
\hline II & 2.60 & 0.9261 & 0.0635 & 0.0104 & 2.61 & 0.9464 & 0.0444 & 0.0092 \\
\hline III & 2.61 & $4.5 \times 10^{-4}$ & 0.0006 & 0.9990 & 2.61 & $1.6 \times 10^{-4}$ & 0.0003 & 0.9995 \\
\hline I & 3.52 & 0.8794 & 0.1040 & 0.0166 & 3.53 & 0.8648 & 0.1290 & 0.0061 \\
\hline II & 3.53 & 0.7445 & 0.2476 & 0.0078 & 3.53 & 0.7392 & 0.2533 & 0.0075 \\
\hline III & 3.53 & $4.9 \times 10^{-4}$ & 0.0027 & 0.9968 & 3.53 & $1.5 \times 10^{-4}$ & 0.0024 & 0.9975 \\
\hline I & 4.59 & 0.7744 & 0.2079 & 0.0177 & 4.59 & 0.7361 & 0.2578 & 0.0061 \\
\hline II & 4.59 & 0.6348 & 0.3591 & 0.0062 & 4.59 & 0.5994 & 0.3941 & 0.0065 \\
\hline III & 4.58 & $5.5 \times 10^{-4}$ & 0.0051 & 0.9944 & 4.59 & $1.3 \times 10^{-4}$ & 0.0045 & 0.9953 \\
\hline I & 6.04 & 0.6062 & 0.3766 & 0.0172 & 6.05 & 0.5404 & 0.4537 & 0.0059 \\
\hline II & 6.04 & 0.5455 & 0.4495 & 0.0050 & 6.05 & 0.5066 & 0.4875 & 0.0059 \\
\hline \multirow[t]{2}{*}{ III } & 6.06 & $4.4 \times 10^{-4}$ & 0.0078 & 0.9918 & 6.05 & $1.1 \times 10^{-4}$ & 0.0073 & 0.9926 \\
\hline & \multicolumn{4}{|c|}{$T=353.18 \mathrm{~K}$} & \multicolumn{4}{|c|}{$T=353.18 \mathrm{~K}$} \\
\hline I & 3.70 & 0.9317 & 0.0417 & 0.0266 & 3.71 & 0.9394 & 0.0510 & 0.0096 \\
\hline II & 3.71 & 0.8924 & 0.0930 & 0.0146 & 3.71 & 0.8956 & 0.0921 & 0.0123 \\
\hline
\end{tabular}


Table 2: Experimental VLLE data and SAFT-VR calculations for (propane $(1)+$ carbon dioxide $(2)+$ water $(3))$ (continued).

\begin{tabular}{|c|c|c|c|c|c|c|c|c|}
\hline Phase & $p / \mathrm{MPa}$ & $x_{1}^{\exp }$ & $x_{2}^{\exp }$ & $x_{3}^{\exp }$ & $p / \mathrm{MPa}$ & $x_{1}^{\text {pred }}$ & $x_{2}^{\text {pred }}$ & $x_{3}^{\text {pred }}$ \\
\hline III & 3.71 & $6.5 \times 10^{-4}$ & 0.0009 & 0.9985 & 3.71 & $1.6 \times 10^{-4}$ & 0.0008 & 0.9990 \\
\hline I & 4.21 & 0.8865 & 0.0862 & 0.0273 & 4.21 & 0.8831 & 0.1073 & 0.0096 \\
\hline II & 4.22 & 0.8281 & 0.1614 & 0.0105 & 4.21 & 0.8184 & 0.1703 & 0.0114 \\
\hline III & 4.21 & $6.7 \times 10^{-4}$ & 0.0019 & 0.9975 & 4.21 & $1.5 \times 10^{-4}$ & 0.0017 & 0.9982 \\
\hline I & 4.80 & 0.8323 & 0.1389 & 0.0288 & 4.80 & 0.8144 & 0.1759 & 0.0096 \\
\hline II & 4.79 & 0.7744 & 0.2166 & 0.0089 & 4.80 & 0.7501 & 0.2393 & 0.0106 \\
\hline III & 4.80 & $6.6 \times 10^{-4}$ & 0.0030 & 0.9964 & 4.80 & $1.4 \times 10^{-4}$ & 0.0027 & 0.9972 \\
\hline I & 5.25 & 0.7866 & 0.1857 & 0.0277 & 5.25 & 0.7568 & 0.2336 & 0.0096 \\
\hline II & 5.26 & 0.7453 & 0.2460 & 0.0087 & 5.25 & 0.7144 & 0.2756 & 0.0100 \\
\hline III & 5.25 & $4.8 \times 10^{-4}$ & 0.0036 & 0.9959 & 5.25 & $1.4 \times 10^{-4}$ & 0.0034 & 0.9964 \\
\hline
\end{tabular}

Table 3: Experimental LLE data for (propane $(1)+$ carbon dioxide $(2)+$ water $(3)$ ) at the critical point between the propane-rich and $\mathrm{CO}_{2}$-rich phases (the combination of both phases is referred here as $\mathrm{CO}_{2}$-rich phase) in presence of a water-rich phase, or upper critical end point. The phases are labelled as II and III for the $\mathrm{CO}_{2}$-rich and the water-rich phases, respectively.

\begin{tabular}{|c|c|c|c|c|c|c|c|}
\hline \multirow[b]{2}{*}{$T / \mathrm{K}$} & \multirow[b]{2}{*}{$p / \mathrm{MPa}$} & \multicolumn{3}{|c|}{ Phase II } & \multicolumn{3}{|c|}{ Phase III } \\
\hline & & $x_{1}^{\exp }$ & $x_{2}^{\exp }$ & $x_{3}^{\exp }$ & $x_{1}^{\exp }$ & $x_{2}^{\exp }$ & $x_{3}^{\exp }$ \\
\hline 311.10 & 6.71 & 0.2140 & 0.7814 & 0.0046 & $1.6 \times 10^{-4}$ & 0.0168 & 0.9830 \\
\hline 323.01 & 6.68 & 0.3618 & 0.6335 & 0.0048 & $2.8 \times 10^{-4}$ & 0.0125 & 0.9873 \\
\hline 338.10 & 6.24 & 0.5445 & 0.4359 & 0.0195 & $5.2 \times 10^{-4}$ & 0.0084 & 0.9911 \\
\hline 353.18 & 5.52 & 0.7404 & 0.2339 & 0.0258 & $4.5 \times 10^{-4}$ & 0.0040 & 0.9955 \\
\hline
\end{tabular}


Table 4: Combined standard uncertainty $u_{\mathrm{c}}\left(x_{i}\right)$, standard deviations $\sigma_{x_{i}}$ and overall uncertainty $U\left(x_{i}\right)$ for the composition measurements of the system (propane $(1)+$ carbon dioxide $(2)+$ water $(3)$ ) in mole fraction. The phases are labelled as I, II and III for the propane-rich, $\mathrm{CO}_{2}$-rich and water-rich phases, respectively.

\begin{tabular}{|c|c|c|c|c|c|c|c|c|c|}
\hline & \multicolumn{3}{|c|}{ Phase I } & \multicolumn{3}{|c|}{ Phase II } & \multicolumn{3}{|c|}{ Phase III } \\
\hline & $x_{1}$ & $x_{2}$ & $x_{3}$ & $x_{1}$ & $x_{2}$ & $x_{3}$ & $x_{1}$ & $x_{2}$ & $x_{3}$ \\
\hline$u_{\mathrm{c}}\left(x_{i}\right)$ & $5 \times 10^{-3}$ & $5 \times 10^{-3}$ & $4 \times 10^{-4}$ & $7 \times 10^{-3}$ & $7 \times 10^{-3}$ & $2 \times 10^{-4}$ & $1 \times 10^{-5}$ & $1 \times 10^{-4}$ & $1 \times 10^{-4}$ \\
\hline$\sigma_{x_{i}}$ & $2 \times 10^{-3}$ & $1 \times 10^{-3}$ & $2 \times 10^{-3}$ & $1 \times 10^{-3}$ & $1 \times 10^{-3}$ & $1 \times 10^{-3}$ & $4 \times 10^{-5}$ & $2 \times 10^{-4}$ & $2 \times 10^{-4}$ \\
\hline$U\left(x_{i}\right)$ & $5 \times 10^{-3}$ & $5 \times 10^{-3}$ & $2 \times 10^{-3}$ & $7 \times 10^{-3}$ & $7 \times 10^{-3}$ & $1 \times 10^{-3}$ & $5 \times 10^{-5}$ & $2 \times 10^{-4}$ & $2 \times 10^{-4}$ \\
\hline
\end{tabular}

Table 5: SAFT-VR intermolecular model parameters ${ }^{a}$ used for modelling the behaviour of the pure components.

\begin{tabular}{cccccccc}
\hline \hline & Reference & $m$ & $\sigma_{i i} / \AA$ & $\left(\varepsilon_{i i} / k_{\mathrm{B}}\right) / \mathrm{K}$ & $\lambda_{i i}$ & $\left(\varepsilon_{i i}^{\mathrm{HB}} / k_{\mathrm{B}}\right) / \mathrm{K}$ & $r_{c}{ }_{i i}^{\mathrm{HB}} / \AA$ \\
\hline $\mathrm{CO}_{2}$ & 76,77 & 2.0 & $3.1364^{\mathrm{b}}$ & $168.89^{\mathrm{b}}$ & 1.5157 & & \\
$\mathrm{C}_{3} \mathrm{H}_{8}$ & 76,77 & 1.6667 & $4.2249^{\mathrm{b}}$ & $204.87^{\mathrm{b}}$ & 1.5531 & & \\
$\mathrm{H}_{2} \mathrm{O}$ & 83 & 1.0 & 3.0342 & 250.00 & 1.7889 & 1400.00 & 2.10822 \\
\hline \hline
\end{tabular}

${ }^{a} m$ is the number of square-well segments in the molecule, $\sigma_{i i}$ is the hard-core diameter, $\lambda_{i i}$ and $\varepsilon_{i i}$ are the range and the depth of the square-well potential, respectively, and $r_{c}{ }_{i i}^{\mathrm{HB}}$ and $\varepsilon_{i i}^{\mathrm{HB}}$ are those of the hydrogen-bonding interaction.

${ }^{b}$ Parameters re-scaled to the experimental critical point. 


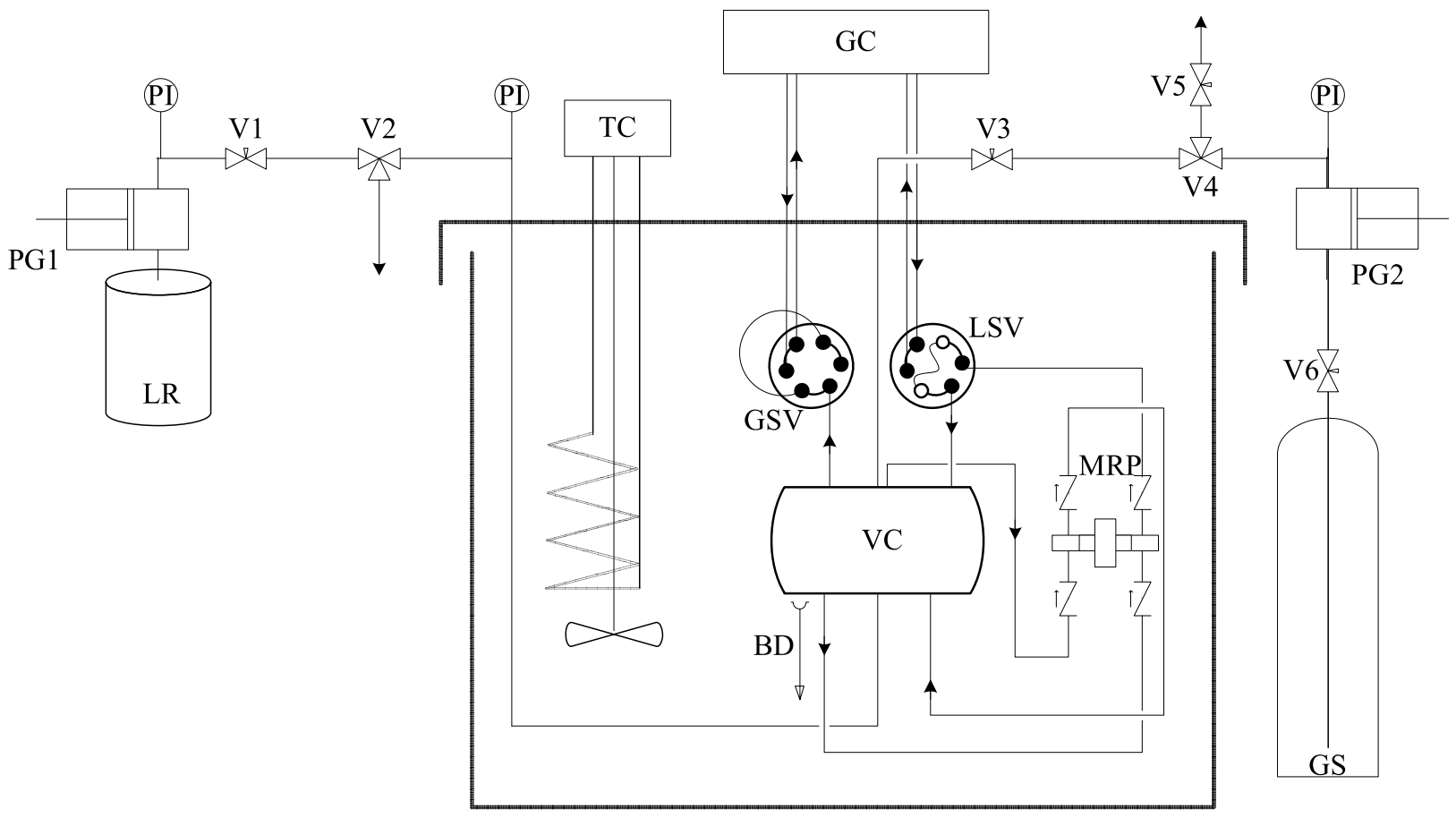

Figure 1: Schematic diagram of the static-analytical apparatus. The following components are depicted: view-cell, VC; magnetic recirculation pump, MRP; liquid sampling valve, LSV; gas sampling valve, GSV; gas-chromatograph, GC; temperature controller, TC; pressure transducers, PI; pressure generators, PG1 and PG2; bursting-disc, BD; liquid reservoir, LR and gas cylinder, GS. 

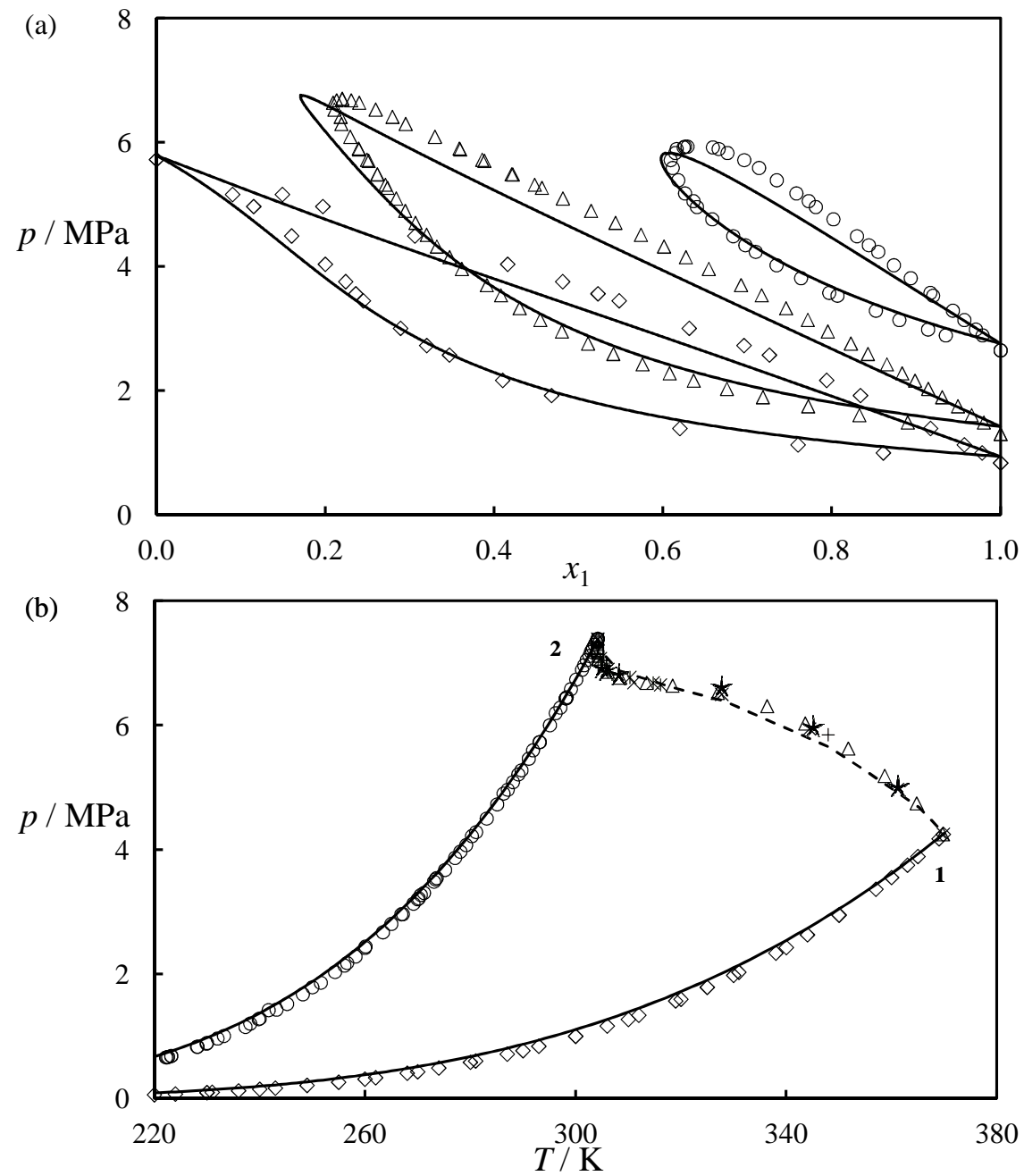

Figure 2: Isothermal pressure-composition $(p, x)(\mathrm{a})$ and $(p, T)(\mathrm{b})$ phase diagram for the (propane $(1)+$ carbon dioxide (2)) mixture. In (a) the symbols correspond to published VLE experimental data for the system at: $\diamond, T=293.15 \mathrm{~K}$ [98]; $\Delta, T=311.05 \mathrm{~K}$ [99] and $\mathrm{O}, T=344.43 \mathrm{~K}$ [99]. In (b) the symbols correspond to the following experimental data: $\diamond$, vapour pressure of propane $[100,101]$; $\bigcirc$, vapour pressure of carbon dioxide [102-107]; the rest of the symbols correspond to critical data points for the mixture: $\star$, Ref. [108]; 口, Ref. [109]; +, Ref. [110]; $\Delta$, Ref. [111]; ×, Ref. [112]; *, Ref. [113]. The curves in (a) correspond to predictions obtained with SAFT-VR using the $k_{i j}=0.082$ value calculated by the extended Hudson and McCoubrey combining rules at the experimental temperatures. In (b) the continuous curves correspond to the calculated vapour pressure for the pure components, whereas the discontinuous curve corresponds to the predicted critical locus with the same $k_{i j}$ value. 


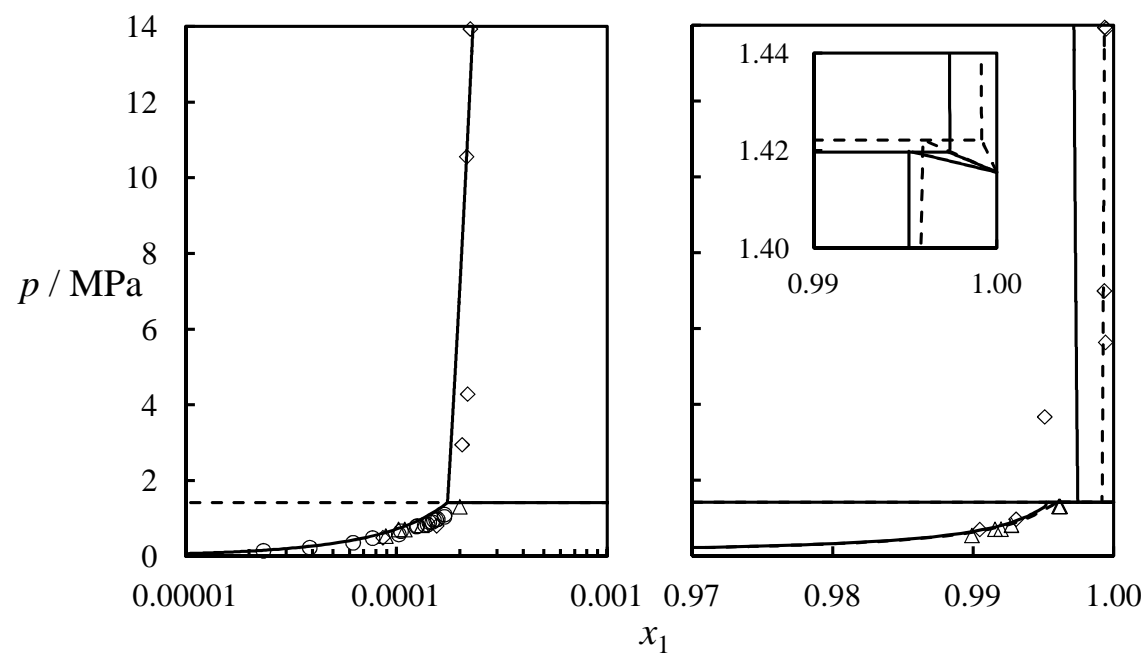

Figure 3: Isothermal pressure-composition $(p, x)$ phase diagram for the (propane $(1)+$ water $(2))$ mixture at $T=310.93 \mathrm{~K}$ showing an amplified image of both saturated phases. The open symbols correspond to published experimental VLE and LLE phase equilibrium data at: $\diamond, T=310.93 \mathrm{~K}$ [42]; O, $T=310.93 \mathrm{~K}$ [114]; $\Delta, T=310.93 \mathrm{~K}[115]$. The continuous curve corresponds to calculations obtained with SAFT-VR using $k_{i j}=-0.99$ and $\gamma_{i j}=0.2225$. The discontinuous curve corresponds to calculations obtained with SAFT-VR using $k_{i j}=0.3006$ and $\gamma_{i j}=0$. Note that the discontinuous curve corresponding to the calculations of the water-rich phase is out of range and therefore not plotted in the figure. 


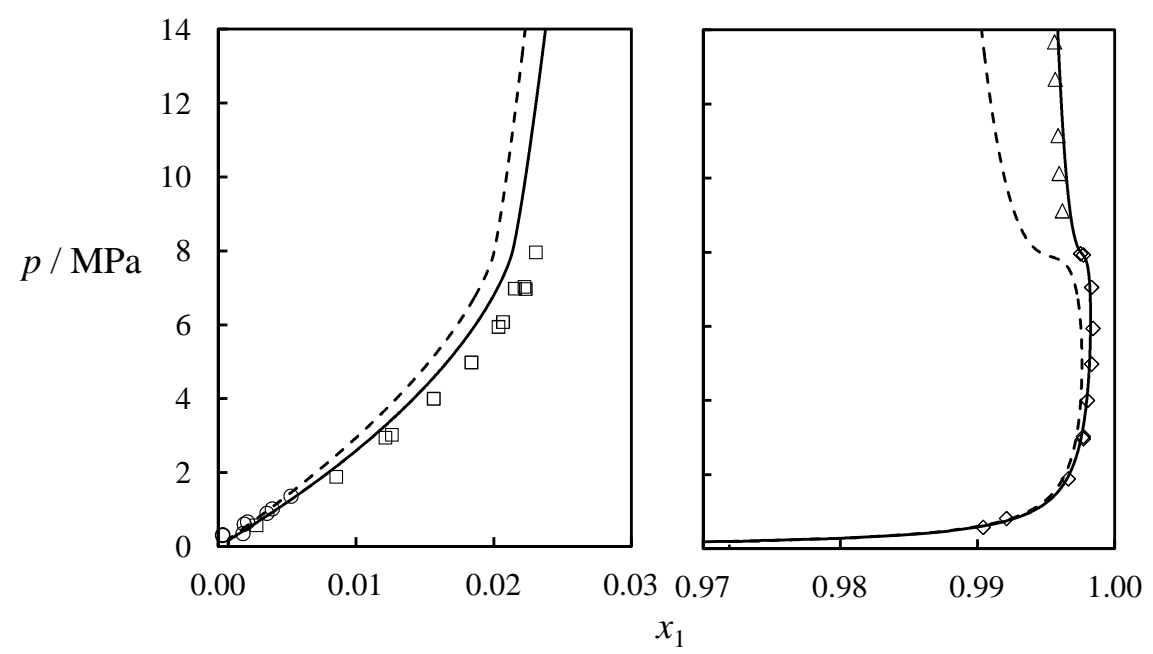

Figure 4: Isothermal pressure-composition $(p, x)$ phase diagram for the (carbon dioxide $(1)+$ water $(2))$ mixture at $T=308 \mathrm{~K}$ showing an amplified image of both saturated phases. The open symbols correspond to published experimental VLE phase equilibrium data at: $\Delta, T=308.15 \mathrm{~K}[116] ; \diamond, T=308.21 \mathrm{~K}[66]$; ○, $T=308.15 \mathrm{~K}[117] ;$ ㅁ, $T=308.20 \mathrm{~K}$ [66]. The continuous curve corresponds to calculations obtained with SAFT-VR using $k_{i j}=-0.6228$ and $\gamma_{i j}=0.1358$. The discontinuous curve corresponds to calculations obtained with SAFT-VR using $k_{i j}=-0.1966$ and $\gamma_{i j}=0$. 


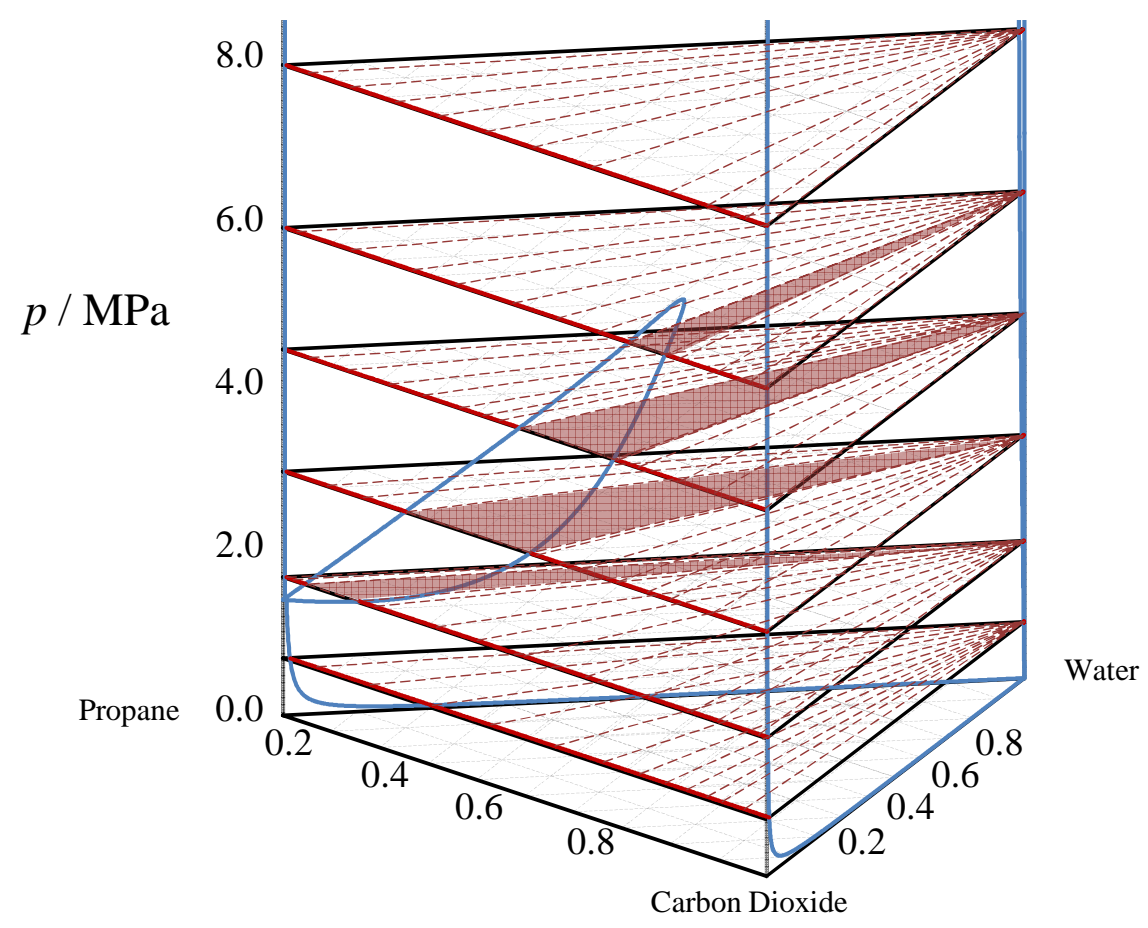

Figure 5: Isothermal pressure-composition $(p, x)$ prismatic diagram for the (propane + carbon dioxide + water) system at $T=311.10 \mathrm{~K}$ calculated with SAFT-VR. Regions of three-phase equilibria appear coloured in light red. Regions of two-phase equilibria appear delimited by continuous thick red curves with some tie-lines traced with thin dashed red lines. Small regions of one-phase equilibria appear in the outer regions delimited by the continuous thick red curves. The two phase coexisting regions for the binary subsystems appear in the lateral sides of the prismatic diagram with a continuous blue line. 

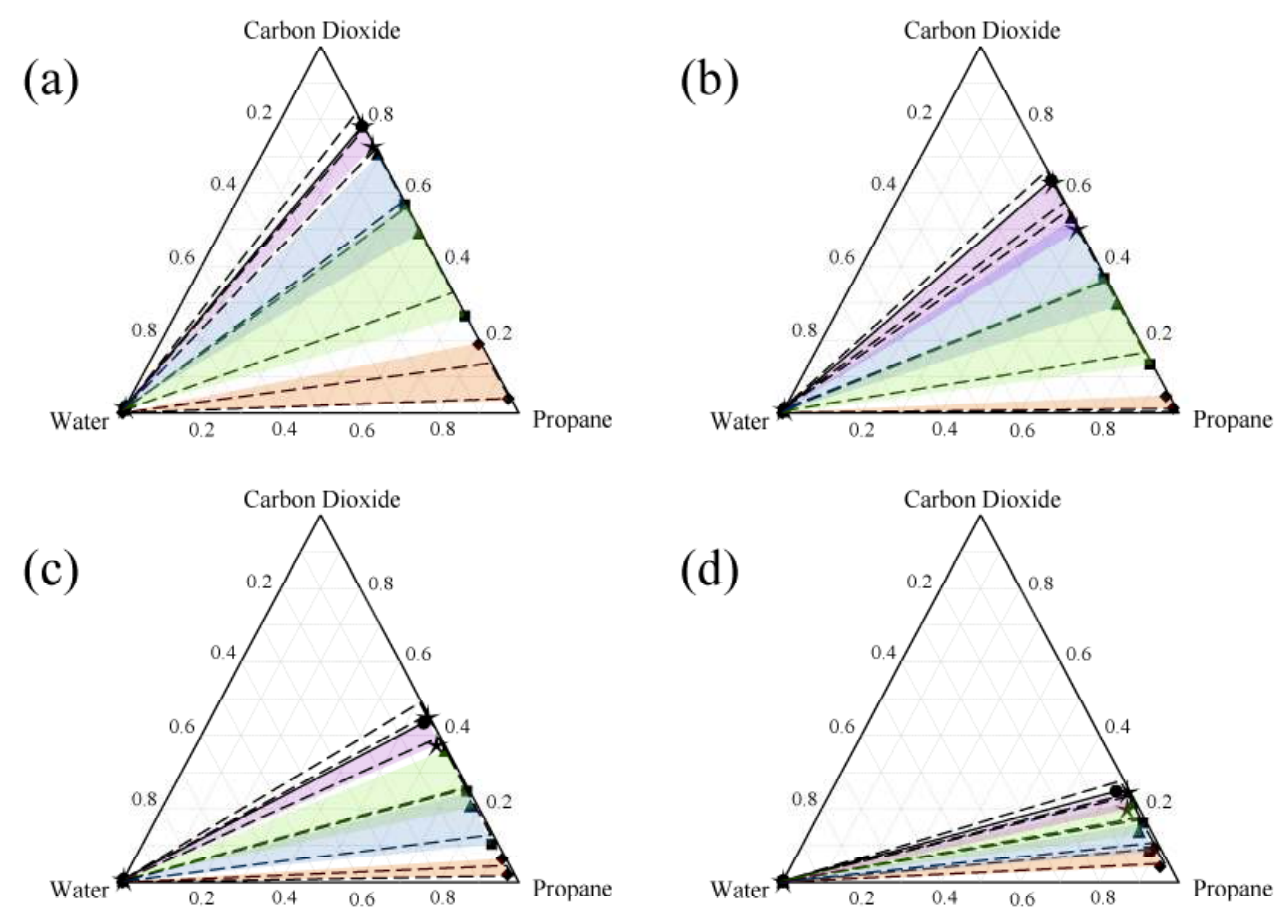

Figure 6: Isothermal composition diagram for the (propane + carbon dioxide + water) system at (a) $T=$ $311.10 \mathrm{~K},(\mathrm{~b}) T=323.01 \mathrm{~K},(\mathrm{c}) T=338.10 \mathrm{~K}$ and $(\mathrm{d}) T=353.18 \mathrm{~K}$. The symbols represent VLLE data points measured in this work at average pressure: (a) $p=1.67 \mathrm{MPa} ; \mathbf{-}, p=3.48 \mathrm{MPa} ; \mathbf{\Lambda}, p=4.96 \mathrm{MPa}$; $\star, p=6.44 \mathrm{MPa} ; \bullet$ and $p=6.71 \mathrm{MPa} ;(\mathrm{b}) \bullet, p=1.86 \mathrm{MPa} ; \mathbf{\square}, p=3.02 \mathrm{MPa} ; \boldsymbol{\Lambda}, p=4.46 \mathrm{MPa} ; \star$, $p=6.00 \mathrm{MPa} ; \bullet$ and $p=6.68 \mathrm{MPa} ;(\mathrm{c}) \bullet, p=2.60 \mathrm{MPa} ; \boldsymbol{\mathbf { }}, p=3.53 \mathrm{MPa} ; \boldsymbol{\Lambda}, p=4.59 \mathrm{MPa} ; \star, p=6.04 \mathrm{MPa}$ and $\bullet, p=6.24 \mathrm{MPa}$; (d) $p=3.71 \mathrm{MPa} ; \boldsymbol{\varpi}, p=4.22 \mathrm{MPa} ; \boldsymbol{\Lambda}, p=4.79 \mathrm{MPa} ; \star, p=5.26 \mathrm{MPa}$ and $\bullet$ $p=5.52 \mathrm{MPa}$. The discontinuous curves are SAFT-VR predictions of the three-phase equilibrium region for every pressure data-point plotted and the shadowed areas emphasise the experimental three-phase regions. The continuous line is the measured tie-line between the two coexisting phases that remain slightly above the critical point between the $\mathrm{CO}_{2}$-rich and the propane-rich phases. 


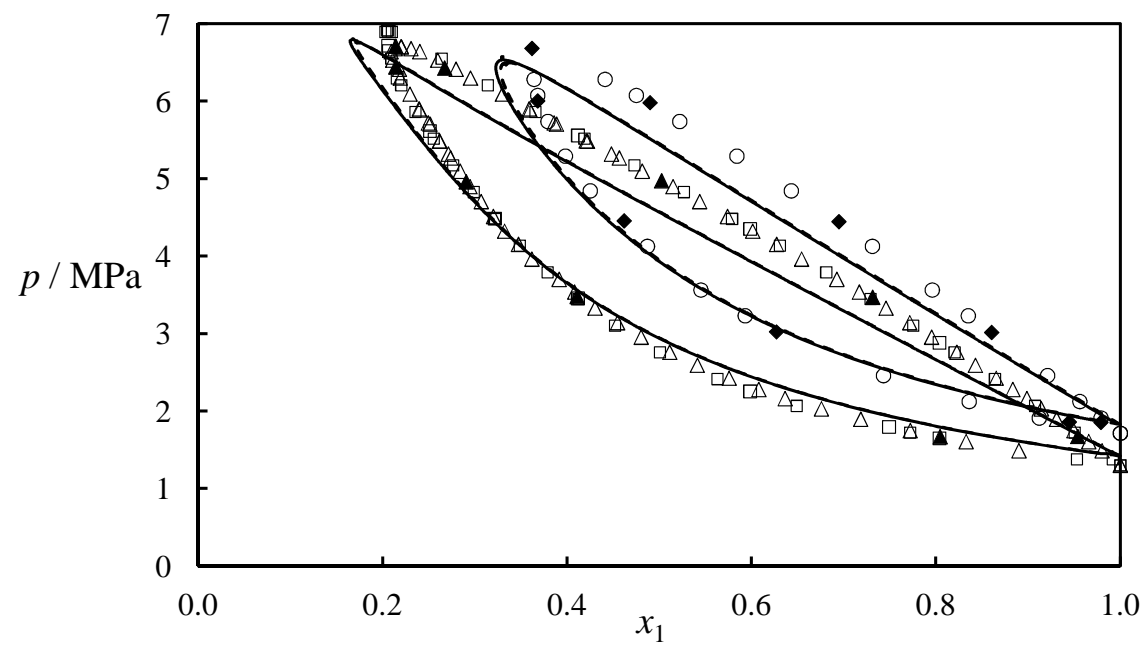

Figure 7: Isothermal pressure-composition $(p, x)$ phase diagram for the (propane $(1)+$ carbon dioxide (2) + water (3)) system. The filled symbols represent data gathered during this work for the propanerich and the carbon dioxide-rich phases under VLLE conditions and temperatures: $\mathbf{\Delta}, T=311.10 \mathrm{~K}$; $T=323.01 \mathrm{~K}$. The open symbols correspond to measurements for the binary (propane + carbon dioxide) at: $\square, T=310.93 \mathrm{~K}$ [118]; $\Delta, T=311.05 \mathrm{~K}$ [99] and $\circ, T=323.15 \mathrm{~K}$ [98]. The continuous curves correspond to the SAFT-VR predictions for the propane-rich and the carbon dioxide-rich phases in the ternary system at conditions of VLLE equilibria. The discontinuous curves correspond to the SAFT-VR predictions for the binary system (propane + carbon dioxide). 


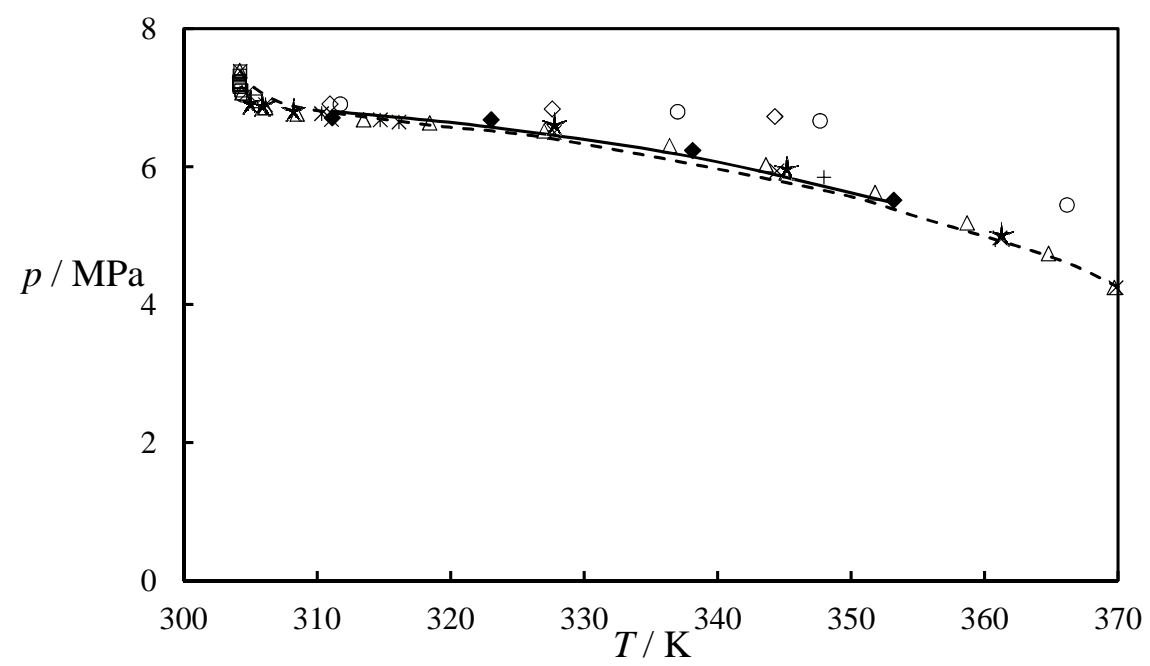

Figure 8: Experimental $(p, T)$ critical locus. The filled triangles, $\diamond$, correspond to measurements of upper critical end points between the $\mathrm{CO}_{2}$-rich and the propane-rich phases in the presence of a third water-rich phase visually observed in this work. The open symbols correspond to critical data points for the binary system (propane + carbon dioxide): $\diamond$, Ref. [118]; O, Ref. [119]; $\star$, Ref. [108]; $\square$, Ref. [109]; +, Ref. [110]; $\Delta$, Ref. [111]; $\times$, Ref. [112]; *, Ref. [113]. The continuous curve corresponds to the calculations with SAFT-VR for the upper critical end line in the ternary at the conditions experimentally studied. The discontinuous curve corresponds to the calculations with SAFT-VR for the critical line in the binary. 


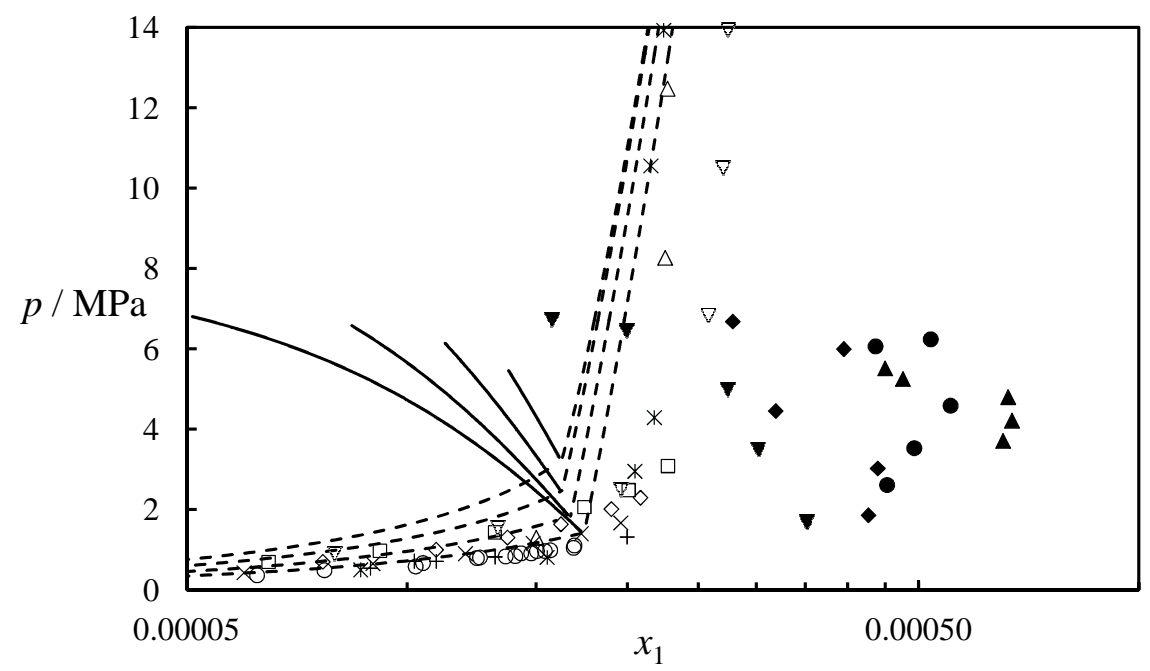

Figure 9: Isothermal pressure-composition $(p, x)$ phase diagram for the (propane $(1)+$ carbon dioxide $(2)$ + water (3)) system showing the propane content in the water-rich phase under VLLE conditions. The

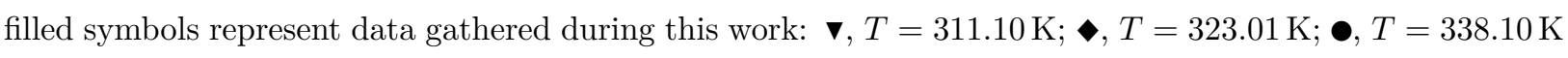
and $\mathbf{\Lambda}, T=353.18 \mathrm{~K}$. The open symbols correspond to published data for the solubility of propane in the water-rich phase in the binary (propane + water) at $*, T=310.93 \mathrm{~K}[42] ; \circ, T=310.93 \mathrm{~K}[114]$; +, $T=310.93 \mathrm{~K}$ [115]; $\times, T=323.13 \mathrm{~K}[46] ; \diamond, T=338.15 \mathrm{~K}$ [46]; $\Delta, T=329.26 \mathrm{~K}$ [42]; , $T=353.18 \mathrm{~K}[46]$ and $\nabla, T=360.93 \mathrm{~K}[42]$. The continuous curves correspond to the SAFT-VR predictions for the water-rich phase in the ternary system at conditions of VLLE equilibria at the same temperatures, increasing from left to right. The discontinuous curves correspond to the SAFT-VR predictions of the propane-rich phase in the (propane + water) binary system, at the same temperatures, increasing from right to left. 


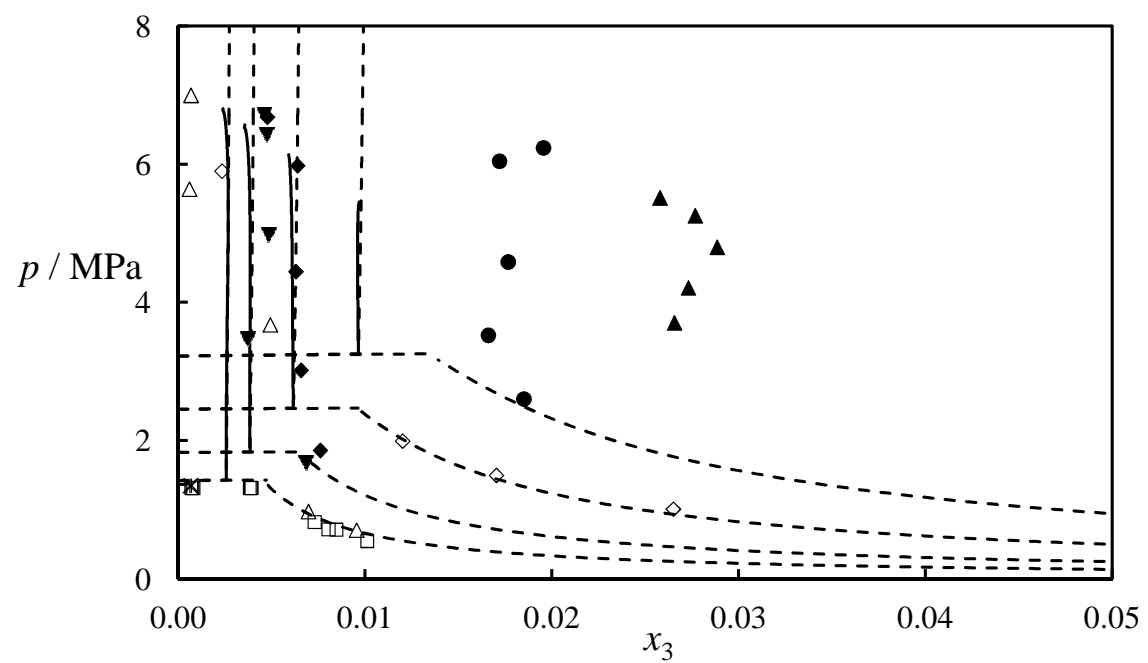

Figure 10: Isothermal pressure-composition $(p, x)$ phase diagram for the (propane (1) + carbon dioxide (2) + water (3)) system showing the water content in the propane-rich liquid phase under VLLE conditions. The filled symbols represent data gathered during this work: $\mathbf{v}, T=311.10 \mathrm{~K} ; \bullet, T=323.01 \mathrm{~K} ; \bullet, T=338.10 \mathrm{~K}$ and $\boldsymbol{\Delta}, T=353.18 \mathrm{~K}$. The open symbols correspond to published data for the solubility of water in the propane-rich phase in the binary (propane + water) at $\Delta, T=310.93 \mathrm{~K}[42]$; $\square, T=310.93 \mathrm{~K}[115]$; $*$, $T=311.98 \mathrm{~K}[42]$ and $\diamond, T=338.71 \mathrm{~K}[42]$. The continuous curves correspond to the SAFT-VR predictions for the propane-rich phase in the ternary system at conditions of VLLE equilibria at the same temperatures, increasing from left to right. The discontinuous curves correspond to the SAFT-VR predictions of the propane-rich phase in the (propane + water) binary system. 


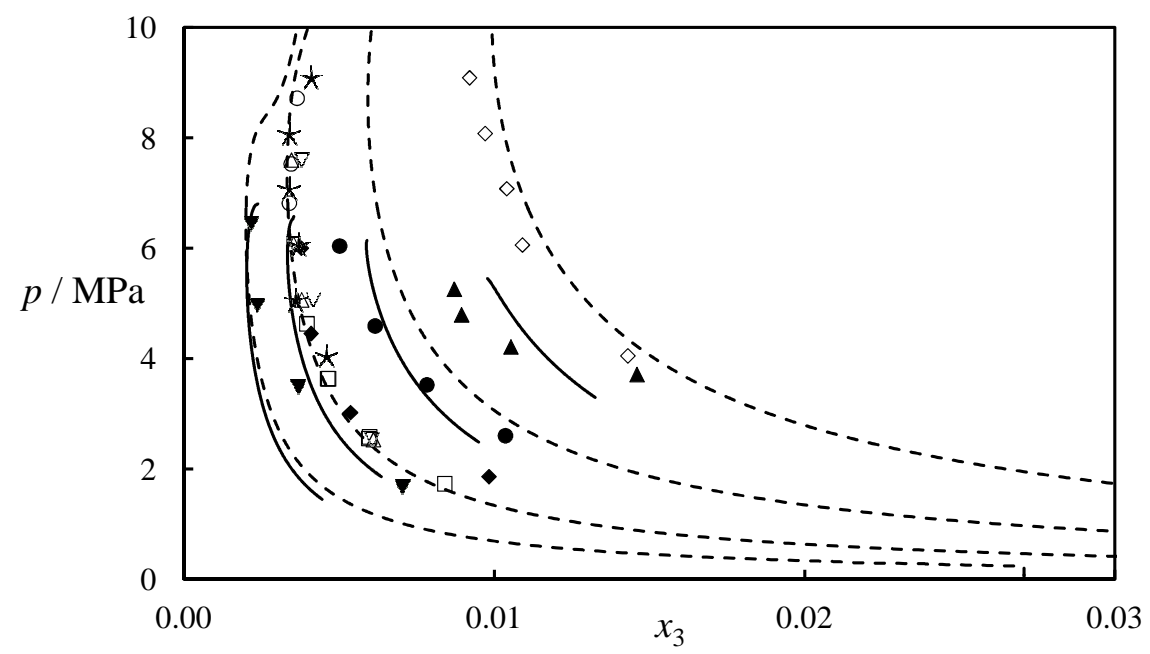

Figure 11: Isothermal pressure-composition $(p, x)$ phase diagram for the (propane (1) + carbon dioxide (2) + water (3)) system showing the water content in the $\mathrm{CO}_{2}$-rich phase under VLLE conditions. The filled

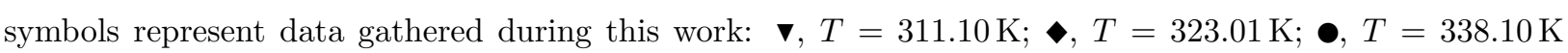
and $\boldsymbol{\Lambda}, T=353.18 \mathrm{~K}$. The open symbols correspond to published data for the solubility of water in the $\mathrm{CO}_{2}$-rich phase in the binary system (carbon dioxide + water) at conditions: $\square, T=323.15 \mathrm{~K}[120]$; $\mathrm{O}$, $T=323.15 \mathrm{~K}[93] ; \Delta, T=323.15 \mathrm{~K}[95] ; \star, T=323.2 \mathrm{~K}[121] ; \nabla, T=323.15 \mathrm{~K}[122]$ and $\diamond, T=353.1 \mathrm{~K}[121]$. The continuous curves correspond to the SAFT-VR predictions for the $\mathrm{CO}_{2}$-rich phase in the ternary system at conditions of VLLE equilibria. The discontinuous curves correspond to the SAFT-VR predictions of the $\mathrm{CO}_{2}$-rich phase in the (carbon dioxide + water) binary system. 


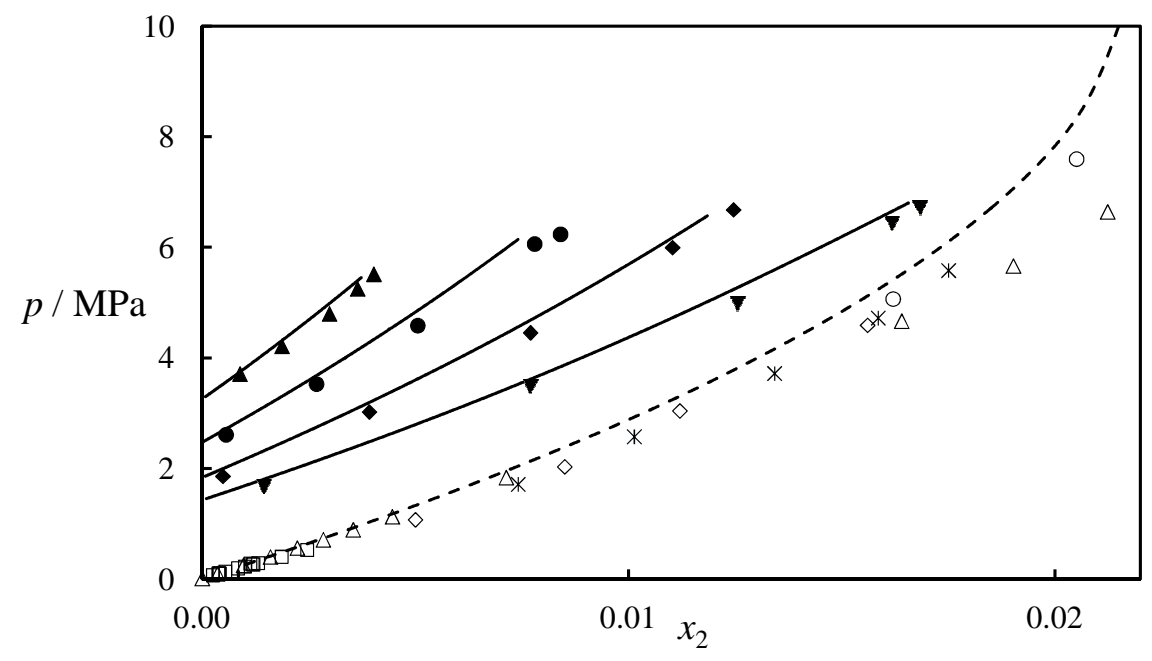

Figure 12: Pressure-composition $(p, x)$ phase diagram for the (propane $(1)+$ carbon dioxide $(2)+$ water $(3))$ system showing the solubility of $\mathrm{CO}_{2}$ in the water-rich phase under VLLE conditions. The filled symbols represent data gathered during this work: $\mathbf{\nabla}, T=311.10 \mathrm{~K} ; \bullet, T=323.01 \mathrm{~K} ; \boldsymbol{\bullet}, T=338.10 \mathrm{~K}$ and $\mathbf{\Delta}$, $T=353.18 \mathrm{~K}$. The open symbols correspond to the solubility in the binary (carbon dioxide + water) at $\Delta$, $T=313.2 \mathrm{~K}[123] ; \diamond, T=313.0 \mathrm{~K}$ [124]; 口, $T=313.2 \mathrm{~K}[125]$; O, $T=313.15 \mathrm{~K}$ [94]; $*, T=313.15 \mathrm{~K}$ [126]. The continuous curves correspond to the SAFT-VR predictions for the water-rich phase in the ternary system at conditions of VLLE equilibria. The discontinuous curves correspond to the SAFT-VR predictions of the water-rich phase in the (carbon dioxide + water) binary system. 


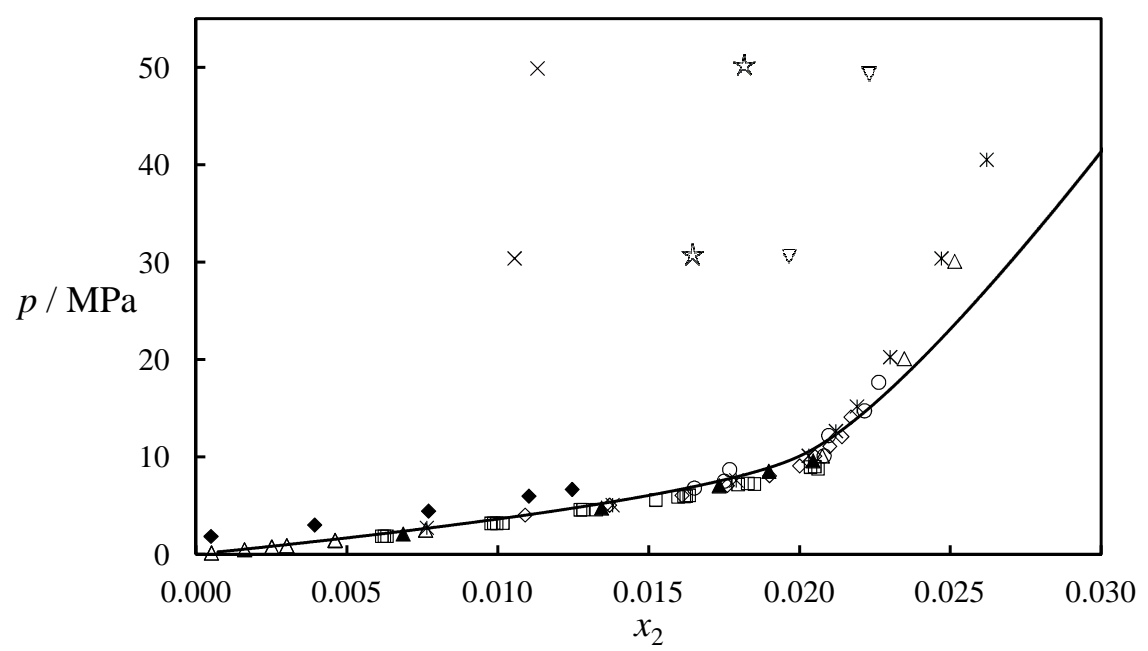

Figure 13: Isothermal pressure-composition $(p, x)$ phase diagram comparing the solubility of carbon dioxide in the water-rich liquid phase of the system (methane (1) + carbon dioxide (2) + water(3)) to that of (carbon dioxide + water). Part of the open symbols correspond to published data for the solubility of carbon dioxide in the aqueous phase of (methane + carbon dioxide + water) at $T \simeq 324 \mathrm{~K}$ and VLE conditions [12], where the composition of the vapour phase is around $\times, y(1) \simeq 0.7 ; \star, y(1) \simeq 0.4$ and $\nabla, y(1) \simeq 0.2$; the remaining open symbols correspond to the solubility in the binary (carbon dioxide + water) at $\Delta, T=323.15 \mathrm{~K}[127]$; *, $T=323.15 \mathrm{~K}$ [94]; ○, $T=323.15 \mathrm{~K}$ [93]; $\diamond, T=323.2 \mathrm{~K}$ [121]; 口, $T=323.15 \mathrm{~K}$ [128]. For completeness the data gathered in this work for the solubility of carbon dioxide in the aqueous phase of each ternary is also represented in the plot as filled symbols: $\bullet$, for (propane + carbon dioxide + water) at $T=323.01 \mathrm{~K}$ and VLLE conditions; $\boldsymbol{\Delta}$, for ( $n$-decane + carbon dioxide + water) at $T=323.08 \mathrm{~K}$ and VLLE conditions. The continuous curve corresponds to the SAFT-VR predictions relative to the binary mixture. 